\title{
Bundle sheath extensions affect leaf structural and physiological plasticity in response to irradiance
}

\author{
Maria Antonia M. Barbosa ${ }^{1}$ | Daniel H. Chitwood ${ }^{2}$ | Aristéa A. Azevedo ${ }^{1}$ | \\ Wagner L. Araújo ${ }^{1,4}$ (D) | Dimas M. Ribeiro ${ }^{1}$ (D) । Lázaro E.P. Peres ${ }^{3}$ | Samuel C.V. Martins ${ }^{1}$ । \\ Agustin Zsögön ${ }^{1}$
}

${ }^{1}$ Departamento de Biologia Vegetal, Universidade Federal de Viçosa, CEP 36570900 Viçosa, MG, Brazil

${ }^{2}$ Department of Horticulture, Michigan State University, 48824 East Lansing, MI, USA

${ }^{3}$ Laboratory of Hormonal Control of Plant Development, Departamento de Ciências Biológicas, Escola Superior de Agricultura "Luiz de Queiroz", Universidade de São Paulo, CP 09, 13418-900 Piracicaba, SP, Brazil

${ }^{4}$ Max-Planck Partner Group at the Departamento de Biologia Vegetal, Universidade Federal de Viçosa, 36570-900 Viçosa, MG, Brazil

Correspondence

A. Zsögön, Departamento de Biologia Vegetal, Universidade Federal de Viçosa, CEP 36570900 Viçosa, MG, Brazil.

Email: agustin.zsogon@ufv.br

Funding information

National Council for Scientific and Technological Development (CNPq, Brazil), Grant/ Award Number: 307040/2014-3; Foundation for Research Assistance of the Minas Gerais State (FAPEMIG, Brazil), Grant/Award Number: RED-00053-16

\begin{abstract}
Coordination between structural and physiological traits is key to plants' responses to environmental fluctuations. In heterobaric leaves, bundle sheath extensions (BSEs) increase photosynthetic performance (light-saturated rates of photosynthesis, $A_{\max }$ ) and water transport capacity (leaf hydraulic conductance, $K_{\text {leaf }}$ ). However, it is not clear how BSEs affect these and other leaf developmental and physiological parameters in response to environmental conditions. The obscuravenosa (obv) mutation, found in many commercial tomato varieties, leads to absence of BSEs. We examined structural and physiological traits of tomato heterobaric and homobaric (obv) nearisogenic lines grown at two different irradiance levels. $K_{\text {leaf }}$, minor vein density, and stomatal pore area index decreased with shading in heterobaric but not in homobaric leaves, which show similarly lower values in both conditions. Homobaric plants, on the other hand, showed increased $A_{\text {max }}$, leaf intercellular air spaces, and mesophyll surface area exposed to intercellular airspace $\left(S_{\text {mes }}\right)$ in comparison with heterobaric plants when both were grown in the shade. BSEs further affected carbon isotope discrimination, a proxy for long-term water-use efficiency. BSEs confer plasticity in traits related to leaf structure and function in response to irradiance levels and might act as a hub integrating leaf structure, photosynthetic function, and water supply and demand.
\end{abstract}

\section{KEYWORDS}

Solanum lycopersicum, adaptation, leaf development, leaf hydraulics, Micro-Tom, mutant, obscuravenosa, shading, tomato

\section{I INTRODUCTION}

Leaves have evolved to maximize light capture and optimize $\mathrm{CO}_{2}$ and water vapour exchange with the atmosphere in land plants. Leaf biochemistry and structure are, therefore, strongly coordinated with photosynthetic performance and hydraulic function. Whereas such coordination is important for plant growth and ecological distribution (Nicotra, Cosgrove, Cowling, Schlichting, \& Jones, 2008; Nicotra et al., 2011), it also requires a degree of developmental plasticity to cope with environmental variation given the sessile nature of plants (Schlichting, 1986; Valladares, Gianoli, \& Gómez, 2007). The light environment can be highly variable and dynamic, being particularly effective at influencing leaf structure and function (Terashima, Hanba, Tazoe, Vyas, \& Yano, 2006; Terashima, Miyazawa, \& Hanba, 2001). Leaf anatomy, in turn, can influence $\mathrm{CO}_{2}$ and $\mathrm{H}_{2} \mathrm{O}$ exchanges with the atmosphere (Evans \& Poorter, 2001; Scoffoni et al., 2015). Optimality theory predicts that, under a given set of conditions, all parameters will tend to converge to maximize photosynthesis with the available resources, mainly light, nitrogen, and water (Niinemets, 2012 and references therein).

Rubisco activity, capacity for ribulose-1,5-bisphosphate regeneration, and triose-phosphate export from chloroplasts are key 
biochemical determinants of net photosynthesis rate $(A)$. Photosynthetic carbon assimilation, however, depends not only on the biochemistry of the leaf but also on its diffusive properties, which are strongly dependent on anatomy and morphology (Nunes-Nesi et al., 2016; Terashima, Hanba, Tholen, \& Niinemets, 2011). Strong correlations with $A$ have been found for stomatal distribution between the adaxial and abaxial faces (i.e., amphistomatous or hypostomatous leaves), blade thickness, leaf mass per area, the palisade-to-spongy mesophyll ratio, and the area of mesophyll and chloroplast surfaces facing the intercellular air spaces (Niinemets \& Sack, 2006). All these parameters are highly plastic in response to light (Oguchi, Hikosaka, \& Hirose, 2003; Oguchi, Hikosaka, \& Hirose, 2005; Terashima et al., 2011) and potentially affect how water transport and evaporation occur in the leaf (Sack, Cowan, Jaikumar, \& Holbrook, 2003; Sack \& Frole, 2006). The efficiency of water transport through the leaf is measured as $K_{\text {leaf }}$ (leaf hydraulic conductance; Sack \& Holbrook, 2006), which is highly dynamic and able to vary rapidly with time of day, irradiance, temperature, and water availability (Prado \& Maurel, 2013). Leaf structural traits such as blade thickness, stomatal pore area, and lamina margin dissection, among others, influence $K_{\text {leaf }}$ (Sack \& Holbrook, 2006).

Vein structure and patterning play a critical role in determining both carbon assimilation rate (McAdam et al., 2017) and water distribution within plants (Sack et al., 2012). Water flow through the leaf occurs via xylem conduits within the vascular bundles, which upon entering the lamina from the petiole, rearrange into major and minor veins. Upon leaving the xylem, water transits through the bundle sheath, a layer of compactly arranged parenchymatic cells surrounding the vasculature (Scoffoni et al., 2017; Trifiló, Raimondo, Savi, Lo Gullo, \& Nardini, 2016). Bundle sheaths could behave as flux sensors or "control centres" of leaf water transport, and they are most likely responsible for the high dependence of $K_{\text {leaf }}$ on temperature and irradiance (Leegood, 2008; Ohtsuka, Sack, \& Taneda, 2018). Vertical layers of colourless cells connecting the vascular bundle to the epidermis are present in many eudicots (Esau, 1977). These so-called bundle sheath extensions (BSEs) are most commonly found in minor veins but can occur in veins of any order depending on the species (Wylie, 1943; Wylie, 1952). A topological consequence of the presence of BSEs is the formation of compartments in the lamina, which restricts lateral gas flow and thus allows compartments to maintain gas exchange rates independent of one another (Buckley, Sack, \& Gilbert, 2011; Morison, Lawson, \& Cornic, 2007; Pieruschka, Schurr, Jensen, Wolff, \& Jahnke, 2006). Such leaves, and by extension the species possessing them, are therefore called "heterobaric," as opposed to "homobaric" species lacking BSEs (Neger, 1918).

Large taxonomic surveys have demonstrated that heterobaric species tend to occur more frequently in sunny and dry sites or in the upper stories of climax forests (Kenzo, Ichie, Watanabe, \& Hiromi, 2007), so it was hypothesized that BSEs could fulfil an ecological role by affecting mechanical and physiological parameters in the leaf (Terashima, 1992). Some proposed functions for BSEs (e.g., mechanical support and increased damage resistance) remain hypothetical (Lawson \& Morison, 2006; Read \& Stokes, 2006), whereas others are more broadly supported through experimental work, suggesting that the existence of BSEs could be adaptive (Buckley et al., 2011). For instance, lateral propagation of ice in the lamina was precluded by the sclerenchymatic BSEs in Cinnamomum canphora L, although this effect has only hitherto been described in this species and could depend on the type and number of BSEs in the leaf blade (Hacker \& Neuner, 2007). Hydraulic integration of the lamina was increased by BSEs, which connect the vascular bundle to the epidermis and, therefore, reduce the resistance in the water path between the supply structures (veins) and the water vapour outlets (stomata; Zwieniecki, Brodribb, \& Holbrook, 2007). Lastly, A was increased in leaves with BSEs, possibly due to their optimization of light transmission within the leaf blade (Karabourniotis, Bornman, \& Nikolopoulos, 2000; Nikolopoulos, Liakopoulos, Drossopoulos, \& Karabourniotis, 2002).

We have previously characterized a homobaric mutant that lacks BSEs in the otherwise heterobaric species tomato (Solanum lycopersicum L.; Zsögön, Alves Negrini, Peres, Nguyen, \& Ball, 2015). The homobaric mutant obscuravenosa (obv) reduces $K_{\text {leaf }}$ and stomatal conductance but does not impact $A_{\max }$, nor global carbon economy of the plant. Here, we extend our observations to plants grown under two contrasting irradiance levels, which are known to influence leaf structure (Oguchi et al., 2003; Oguchi et al., 2005; Oguchi, Hikosaka, Hiura, \& Hirose, 2006), $A_{\max }$ (Evans \& Poorter, 2001; Shipley, 2002), and $K_{\text {leaf }}$ (Guyot, Scoffoni, \& Sack, 2012; Scoffoni et al., 2015; Scoffoni, Pou, Cia, \& Sack, 2008). We investigated whether the presence of BSEs could have an impact on the highly plastic nature of leaf development and function in response to different irradiance levels. We hypothesized that homobaric leaves, lacking a key physical feature that increases carbon assimilation and leaf hydraulic integration, would exhibit less plasticity in their response to environmental conditions than heterobaric leaves. By assessing a series of leaf structural and physiological parameters in tomato cultivar Micro-Tom (MT) and the near-isogenic obv mutant, we provide evidence of the potential role of BSEs in the coordination of leaf structure and hydraulics in response to growth irradiance. Finally, we analysed whether dry mass accumulation and tomato fruit yield are affected by the presence of BSEs and irradiance in two different tomato genetic backgrounds (cultivars MT and M82). We discuss the potential role of BSEs in the coordination of leaf structure and function in response to the light environment.

\section{2 | MATERIALS AND METHODS}

\section{1 | Plant material and experimental set-up}

Seeds of the tomato (S. lycopersicum L.) cultivar MT and cultivar M82 were donated by Dr Avram Levy (Weizmann Institute of Science, Israel) and the Tomato Genetics Resource Center (Davis, University of California, CA, USA), respectively. The introgression of the obv into the MT genetic background to generate a near-isogenic line was described previously (Carvalho et al., 2011). The model tomato M82 cultivar harbours the obv mutation, so the experiments were performed on F1 lines obtained by crosses between MT and M82. Both F1 lines have 50\% MT and 50\% M82 genome complement, differing only in the presence or absence of BSEs (described in Table 1). Data were obtained from two independent assays; similar results were found both times. Plants were grown in a greenhouse in Viçosa (642 $\mathrm{m}$ asl, $20^{\circ} 45^{\prime} \mathrm{S} ; 42^{\circ} 51^{\prime} \mathrm{W}$ ), Minas Gerais, Brazil, under semi-controlled conditions. MT background plants were grown during the 
TABLE 1 Description of the plant material used in this study

\begin{tabular}{|c|c|c|c|c|c|}
\hline Parental genotype & MT & MT-obv & M82 & $\mathrm{F} 1 \mathrm{MT} \times \mathrm{M} 82$ & F1 MT-obv $\times$ M82 \\
\hline \multicolumn{6}{|l|}{ Plant height } \\
\hline Genotype & $d w a r f / d w a r f$ & $d w a r f / d w a r f$ & DWARF/DWARF & DWARF/dwarf & DWARF/dwarf \\
\hline \multicolumn{6}{|l|}{ BSEs } \\
\hline Genotype & OBV/OBV & $o b v / o b v$ & $o b v / o b v$ & OBV/obv & $o b v / o b v$ \\
\hline Phenotype & BSEs (clear veins) & No BSEs (dark veins) & No BSEs (dark veins) & BSEs (clear veins) & No BSEs (dark veins) \\
\hline
\end{tabular}

Note. Micro-Tom (MT) and M82 are two tomato cultivars that differ in growth habit due mostly to the presence of a mutant allele of the DWARF gene, which codes for a key enzyme of the brassinosteroid biosynthesis pathway. The molecular identity of OBSCURAVENOSA (OBV) is unknown. MT harbours a functional, dominant allele of OBV, whereas M82 is a mutant (obv). F1 plants are hybrids with a 50/50 MT/M82 genomic complement, differing only in the presence or absence of bundle sheath extensions (BSEs). The F1 plants are otherwise phenotypically indistinguishable from the M82 parent.

months of May to August of 2016 in temperature of $24 / 20^{\circ} \mathrm{C}, 13 / 11-\mathrm{h}$ (day/night) photoperiod. Plants in the M82 background were cultivated during the months of September to December of 2016 with temperature of $26 / 22^{\circ} \mathrm{C}, 12 / 12-\mathrm{h}$ (day/night) photoperiod. Plant cultivation was carried out as described previously (Silva et al., 2018). The experiments were conducted in completely randomized experimental design, in $2 \times 2$ factorial, consisting of two genotypes and two irradiance levels (sun and shade). Plants in the "sun" treatment were exposed to greenhouse conditions, with midday irradiance of $\sim 900 \mu \mathrm{mol}$ photons $\mathrm{m}^{-2} \mathrm{~s}$ ${ }^{-1}$. For the "shade" treatment plants were maintained on a separate bench covered with neutral shade cloth, with a retention capacity of $70 \%$ of sunlight $\left(250-300 \mu \mathrm{mol}\right.$ photons $\mathrm{m}^{-2} \mathrm{~s}^{-1}$ ).

\section{2 | Plant morphology determinations}

Morphological characterization was performed in MT plants 50 days after germination as described (Vicente, Zsögön, Lopo de Sá, Ribeiro, \& Peres, 2015). Specific leaf area (SLA) was calculated through the relationship between leaf area (LA) and dry mass (LDW), as described by the equation SLA $\left(\mathrm{cm}^{2} \mathrm{~g}^{-1}\right)=$ LA/LDW.

Leaflet outline shape was analysed as described in Chitwood et al. (2015). Briefly, leaflet outlines were thresholded using ImageJ (Abramoff, Magalhães, \& Ram, 2004) and converted to .bmp files for analysis in SHAPE (Iwata \& Ukai, 2002), where each leaflet was converted into chaincode, oriented, and decomposed into harmonic coefficients. The harmonic coefficients were then converted into a data frame format and read into R ( $\mathrm{R}$ Core Team, 2018). The Momocs package (Bonhomme et al., 2014) was used to visualize mean leaflet shapes from each genotype/light treatment combination. The prcomp() function was used to perform a principal component analysis on only $A$ and $D$ harmonics so that only symmetric (rather than asymmetric) shape variance was considered (Iwata, Niikura, Matsuura, Takano, \& Ukai, 1998). The results were visualized using ggplot2 (Wickham, 2016).

\section{3 | Light microscopy analyses}

The fully expanded fifth leaf was cleared with $95 \%$ methanol for $48 \mathrm{~h}$ followed by $100 \%$ lactic acid. Stomatal pore area index (SPI) was calculated as (guard cell length) ${ }^{2} \times$ stomatal density for the adaxial and abaxial epidermes and then added up (Sack et al., 2003). Stomatal density was calculated as number of stomata per unit leaf area, stomatal index as the proportion of guard cells to total epidermal cells. Minor vein density was measured as length of minor veins $(<0.05-\mu \mathrm{m}$ diameter) per unit leaf area.

For cross-sectional analyses, samples were collected from the medial region of the fully expanded fifth leaf and fixed in $70 \%$ formalin-acetic acid-alcohol solution for $48 \mathrm{~h}$ and then stored in $70 \%$ $(\mathrm{v} / \mathrm{v})$ aqueous ethanol. The samples were embedded in historesin (Leica Microsystems, Wetzlar, Germany), cut into cross sections (5 $\mathrm{mm}$ ) with an automated rotary microtome (RM2155, Leica Microsystems), and sequentially stained with toluidine blue. Images were obtained in a light microscope (Zeiss, Axioscope A1 model, Thornwood, NY, USA) with attached Axiovision ${ }^{\circledR} 105$ colour image capture system. Anatomical parameters were quantified using Image Pro-Plus ${ }^{\circledR}$ software (version 4.5, Media Cybernetics, Silver Spring, MD, USA).

Mesophyll surface area exposed to intercellular air spaces per leaf area $\left(S_{\text {mes }} / S\right)$ was calculated separately for spongy and palisade tissues as described by Evans, Caemmerer, Setchell, and Hudson (1994). To convert the length in cross sections to the surface area, a curvature correction factor was measured and calculated for each treatment according to Thain (1983) for palisade and spongy cells by measuring their width and height and calculating an average width/height ratio. The curvature factor correction ranged from 1.17 to 1.27 for spongy cells and from 1.38 to 1.45 for palisade cells. All parameters were analysed at least in four different fields of view. $S_{m} / S$ was calculated as a weighted average based on tissue volume fractions.

\section{4 | Anatomical estimation of mesophyll conductance $\left(\mathrm{g}_{\mathrm{m}}\right)$}

The one-dimensional gas diffusion model of Niinemets and Reichstein (2003) as applied by Tosens, Niinemets, Vislap, Eichelmann, and Castro (2012) was employed to estimate the share of different leaf anatomical characteristics in determining mesophyll conductance $\left(g_{\mathrm{m}}\right) . g_{\mathrm{m}}$ as a composite conductance for within-leaf gas and liquid components is given by

$$
g_{\mathrm{m}}=\frac{1}{\frac{1}{g_{\text {ias }}}+\frac{R T_{\mathrm{k}}}{H \cdot g_{\text {liq }}}},
$$

where $g_{\text {ias }}$ is the gas phase conductance inside the leaf from substomatal cavities to outer surface of cell walls, $g_{\text {liq }}$ is the conductance in liquid and 
lipid phases from outer surface of cell walls to chloroplasts, $R$ is the gas constant (8.314 Pa m$\left.{ }^{3} \mathrm{~K}^{-1} \mathrm{~mol}^{-1}\right), T_{\mathrm{k}}$ is the absolute temperature $(\mathrm{K})$, and $H$ is the Henry's law constant $\left(2,938.4 \mathrm{~Pa} \mathrm{~m}^{3} \mathrm{~mol}^{-1}\right) \cdot \mathrm{gm}_{\mathrm{m}}$ is defined as a gas-phase conductance, and thus, $H /\left(R T_{k}\right)$, the dimensionless form of Henry's law constant, is needed to convert gliq to corresponding gasphase equivalent conductance (Niinemets \& Reichstein, 2003). In the model, the gas-phase conductance (and the reciprocal term, $r_{\text {ias }}$ ) is determined by average gas-phase thickness, $\Delta L_{\text {ias }}$, and gas-phase porosity, $f_{\text {ias }}$ (fraction of leaf air space):

$$
g_{\text {ias }}=\frac{1}{r_{\text {ias }}}=\frac{D_{\text {a }} \cdot f_{\text {ias }}}{\Delta} L_{\text {ias }} \cdot S,
$$

where $\varsigma$ is the diffusion path tortuosity $\left(1.57 \mathrm{~m} \mathrm{~m}^{-1}\right.$, value taken from Niinemets \& Reichstein, 2003) and $D_{a}\left(\mathrm{~m}^{2} \mathrm{~s}^{-1}\right)$ is the diffusion coefficient for $\mathrm{CO}_{2}$ in the gas phase $\left(1.51 \times 10^{-5}\right.$ at $\left.25^{\circ} \mathrm{C}\right) . \Delta L_{\text {ias }}$ was taken as half the mesophyll thickness.

$$
g_{\text {liq }}=\frac{S_{m}}{\left(r_{\mathrm{cw}}+r_{\mathrm{pl}}+r_{\mathrm{cyt}}+r_{\mathrm{en}}+r_{\mathrm{st}}\right) S} .
$$

The term $r_{\mathrm{i}}$, where $i$ stands for cell wall (cw), plasma membrane (pl), cytosol (cyt), chloroplast envelope (en), and stroma (st) resistances, is the partial determinants of the liquid-phase diffusion pathway. Cell wall thickness is the main determinant of liquid-phase resistance, and, as we found little variation for this parameter when comparing two studies conducted under different conditions (Berghuijs et al., 2015; Eid Gamel, Elsayed, Bashasha, \& Haroun, 2016), we used the partial determinants of the liquid-phase diffusion pathway described in Berghuijs et al. (2015). In addition, $S_{\text {mes }} / S$, a major determinant of

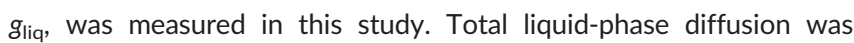
scaled by the $S_{\text {mes }} / S$ as there was little cell wall area free of chloroplasts (Figure $\mathrm{S} 4$ ) reflecting a ratio between chloroplast and mesophyll area exposed to intercellular airspaces $\left(S_{c} / S_{\text {mes }}\right)$ very close to 1.0 as also observed by Galmés et al. (2013).

\section{5 | Carbon isotope composition}

The fully expanded fifth leaf of five plants per treatment was harvested and ground to fine powder. Samples were sent to the Laboratory of Stable Isotopes (CENA, USP, Piracicaba, Brazil), where they were analysed for ${ }^{13} \mathrm{C} /{ }^{12} \mathrm{C}$ ratio using a mass spectrometer coupled to a Dumas elemental analyser ANCA-SL (Europa Scientific, Crewe, UK). Carbon isotope ratios were obtained in $\delta$-notation, where

$$
\delta=\left(\frac{R}{R_{\text {standard }}}\right)-1
$$

and $R$ and $R_{\text {standard }}$ are the isotope ratios of the plant sample and the Vienna Pee Dee Belemnite standard, respectively. $\delta^{13} \mathrm{C}$ of atmospheric $\mathrm{CO}_{2}$ was assumed to be -8 per mil. The $\delta^{13} \mathrm{C}$ values for the samples were then converted to carbon isotopic discrimination values, $\Delta^{13} \mathrm{C}=\left(\delta_{\mathrm{a}}-\delta_{\mathrm{p}}\right) /\left(1+\delta_{\mathrm{p}}\right)$, where $\delta_{\mathrm{a}}$ is the $\delta^{13} \mathrm{C}$ of atmospheric $\mathrm{CO}_{2}$ and $\delta_{\mathrm{p}}$ is the $\delta^{13} \mathrm{C}$ of the plant material (Farquhar \& Sharkey, 1982).

\subsection{Gas exchange and chlorophyll fluorescence determinations}

Gas exchange analyses were performed in MT and M82 plants at 40 and 50 days after germination, respectively. Gas exchange measurements were performed using an open-flow gas exchange system infrared gas analyser model LI-6400XT (LI-COR, Lincoln, NE, USA). The analyses were performed under common conditions for photon flux density $\left(1,000 \mu \mathrm{mol} \mathrm{m} \mathrm{m}^{-2} \mathrm{~s}^{-1}\right.$, from standard LI-COR light-emitting diode source), leaf temperature $\left(25 \pm 0.5^{\circ} \mathrm{C}\right)$, leaf-to-air vapour pressure difference (16.0 $\pm 3.0 \mathrm{mbar}$ ), air flow rate into the chamber $\left(500 \mu \mathrm{mol} \mathrm{s}^{-1}\right)$, and reference $\mathrm{CO}_{2}$ concentration of $400 \mathrm{ppm}$ (injected from a cartridge), using an area of $2 \mathrm{~cm}^{2}$ in the leaf chamber. For dark respiration $\left(R_{\mathrm{d}}\right)$ determination, plants were adapted to the dark at least $1 \mathrm{~h}$ before the measurements, as described by Niinemets, Cescatti, Rodeghiero, and Tosens (2006).

Photochemical efficiency of photosystem II ( $\varphi$ PSII) was determined by measuring the steady-state fluorescence $\left(F_{\mathrm{s}}\right)$ and the maximum fluorescence $\left(F_{m}{ }^{\prime}\right)$, using a pulse of saturating light of approximately $8,000 \mu \mathrm{mol}$ photons $\mathrm{m}^{-2} \mathrm{~s}^{-1}$, as described by Genty, Briantais, and Baker (1989). Photosynthetic light response curves were measured under ambient $\mathrm{O}_{2}$, with reference $\mathrm{CO}_{2}$ set to $400 \mu \mathrm{mol} \mathrm{mol}{ }^{-1}$. After allowing full photosynthetic induction for 30$45 \mathrm{~min}, \mathrm{~A}$ was determined at PPFD steps 1,500, 1,200, 1,000, 800, $600,400,300,200,150,75,50$, and $0 \mu \mathrm{mol} \mathrm{m}^{-2} \mathrm{~s}^{-1}$ at ambient temperature $\left(25^{\circ} \mathrm{C}\right)$ and $\mathrm{CO}_{2}$ concentration $\left(400 \mu \mathrm{mol} \mathrm{mol}{ }^{-1}\right)$. The light saturation point $\left(I_{\mathrm{s}}\right)$, light compensation point $\left(I_{\mathrm{c}}\right)$, light saturation $\mathrm{CO}_{2}$ assimilation rate $\left(A_{\mathrm{PPFD}}\right)$, and the light utilization $(1 / \Phi)$ were calculated from those results. $A / C_{i}$ curves were constructed with step changes $(50,100,150,250,400,500,700,900,1,200,1,300,1,400$, and $1,600 \mu \mathrm{mol} \mathrm{mol}{ }^{-1}$ ) of $\left[\mathrm{CO}_{2}\right]$ under $1,000-\mu \mathrm{mol} \mathrm{m} \mathrm{m}^{-2} \mathrm{~s}^{-1}$ light, at $25^{\circ} \mathrm{C}$ under ambient $\mathrm{O}_{2}$ supply. The maximum rate of carboxylation $\left(V_{c \max }\right)$, rate of photosynthetic electron transport $\left(J_{\max }\right)$, and rate of triose-phosphate utilization were estimated by fitting the mechanistic model of $\mathrm{CO}_{2}$ assimilation proposed by Farquhar, von Caemmerer, and Berry (1980). Additionally, $g_{m}$ was tentatively estimated using the Ethier and Livingston (2004) method, which is based on fitting $A / C_{i}$ curves with a nonrectangular hyperbola version of the FvCB that incorporates $\mathrm{g}_{\mathrm{m}}$ in the model. Corrections for the leakage of $\mathrm{CO}_{2}$ into and out of the leaf chamber of the LI-6400 were applied to all gas exchange data as described by Rodeghiero, Niinemets, and Cescatti (2007) using a $K_{\mathrm{CO} 2}$ estimated as $0.4 \mu \mathrm{mol} \mathrm{s}{ }^{-1}$.

\subsection{Water relations}

Leaf $\left(\Psi_{\mathrm{L}}\right)$ or xylem $\left(\Psi_{\mathrm{X}}\right)$ water potential was measured in the central leaflet of the fifth fully expanded leaf in MT and M82 plants 40 and 50 days of age, respectively, using a Scholander-type pressure chamber (model 1000, PMS Instruments, Albany, NY, USA). $\Psi_{\mathrm{L}}$ was measured in transpiring leaves, whereas $\Psi_{X}$ was obtained from nontranspiring leaflets, assumed to be in equilibrium with the petiole water potential. The nontranspiring leaflet consisted of the lateral leaflet of the same leaf, which was covered with plastic film and foil the night before the measurements. Apparent hydraulic conductance 
( $\left.K_{\text {leaf }}\right)$ was estimated using the transpiration rates and the water potential difference between the transpiring and nontranspiring leaflet according to Ohm's law:

$$
K_{\text {leaf }}=\frac{E}{\left(\Psi_{X}-\Psi_{L}\right)}
$$

where $E$ is the transpiration rate $\left(\mathrm{mmol} \mathrm{m}^{-2} \mathrm{~s}^{-1}\right)$ determined during gas exchange measurements and $\left(\Psi_{\mathrm{L}}-\Psi_{\mathrm{X}}\right)$ corresponds to the pressure gradient between the transpiring and nontranspiring leaflet ( $\mathrm{MPa}$ ). Water potential and hydraulic conductance measurements were performed immediately after gas exchange analysis.

\section{8 | Biochemical determinations}

Biochemical analyses of the leaves were performed in MT and M82 plants 40 and 50 days after germination, respectively. The terminal leaflet of the sixth fully expanded leaf was collected around midday on a cloudless day, instantly frozen in liquid $\mathrm{N}_{2}$, and stored at $-80^{\circ} \mathrm{C}$. Subsequently, the samples were lyophilized at $-48^{\circ} \mathrm{C}$ and macerated with the aid of metal beads in a Mini-Beadbeater-96 type cell disrupter (Biospec Products, Bartlesville, OK, USA). A 10-mg sample of ground tissue was added to pure methanol $(700 \mu \mathrm{l})$, and the mixture was incubated at $70^{\circ} \mathrm{C}$ for $30 \mathrm{~min}$ followed by a centrifugation $(16,200 \mathrm{~g}, 5 \mathrm{~min})$. Supernatant was placed in new tubes in which chloroform and ultrapure water were added ( 375 and $600 \mu$ l, respectively). After new centrifugation $(10,000 \mathrm{~g}, 10 \mathrm{~min})$, the concentrations of hexoses (glucose plus fructose) and sucrose were determined in the aqueous phase by a three-step reaction in which hexokinase, phosphoglucose isomerase, and invertase (Sigma Aldrich) were subsequently added to a reaction buffer containing ATP, NADH, and glucose dehydrogenase (Sigma Aldrich) according to Fernie, Roscher, Ratcliffe, and Kruger (2001). The methanol-insoluble pellet was resuspended by adding $1 \mathrm{ml} 0.2-\mathrm{M} \mathrm{KOH}$ followed by incubation at $95^{\circ} \mathrm{C}$. The resulted solution was used for subsequent protein quantification (Bradford method). Finally, 2-M acetic acid was added (160 $\mu \mathrm{l}$ ) to the resuspended pellet from which starch was quantified by adding hexokinase in a buffer reaction as previously described for sugars. Noteworthy, the above described protocol was previously detailed by Praxedes, DaMatta, Loureiro, Ferrão, and Cordeiro (2006) and Ronchi et al. (2006) and includes some of the recommendations described by Quentin et al. (2015), such as the use of amyloglucosidase for starch extraction and the use of glucose and starch standards. Photosynthetic pigments (chlorophyll $[\mathrm{a}+\mathrm{b}]$ content and carotenoids) were determined in the methanolic extract using the equations described in Porra, Thompson, \& Kriedemann (1989) using a microplate reader.

\subsection{Agronomic parameters (yield and Brix)}

The number of fruits per plant was obtained from fruit counts, and the frequency of green and mature fruits was also determined separately. Fruit average weight was determined after individual weighing of each fruit, using a semianalytical balance with a sensitivity of $0.01 \mathrm{~g}$ (AUY220, Shimadzu, Kyoto, Japan). Yield per plant corresponds to the total weight of fruits per plant. The determination of the soluble solids content ('Brix, which is the percentage of soluble solids by weight) in the fruits was measured with a digital temperature-compensated refractometer, model RTD 45 (Instrutherm ${ }^{\circledR}$, São Paulo, Brazil). Six ripe fruits per plant were evaluated in five replicates per genotype.

\subsection{0 | Statistical analysis}

The data were subjected to analysis of variance using Assistat version 7.6 (http://assistat.com), and the means were compared by Tukey's test at the $5 \%$ level of significance $(P \leq 0.05)$.

\section{3 | RESULTS}

This study was performed on two tomato genetic backgrounds, cultivars MT and M82, and their respective obv mutant near-isogenic lines. First, we conducted a microscopic analysis of terminal leaflet cross sections to confirm that, like all wild-type tomatoes and its wild relatives, MT harbours BSEs in primary (i.e., midrib) and secondary veins of fully expanded leaves (Figure 1a). The obv mutant, on the other hand, lacks these structures, so that the veins appear obscure (hence, the name of the genotype; Figure $1 \mathrm{~b}$ ). Chlorophyll fluorescence imaging revealed that this optical effect is due to the continuity of the palisade mesophyll on the adaxial side and of the spongy mesophyll on the abaxial side in obv, which are both interrupted by BSEs in MT (Figure 1c,d). The BSEs protrude toward the adaxial epidermis as columns of possibly collenchymatic cells with thickened cell walls, whereas they thicken downward and are broadly based upon the lower epidermis (Figure 1e-h). We next conducted a water + dye infiltration assay in the lamina, proving that, under similar pressure, intercellular spaces of the obv mutant were flooded almost twice $(86.1 \%$ vs. $47.3 \%, P=0.012$ ) as much as for MT (Figure S1). Dry patches were observed in MT, which shows that the presence of BSEs in secondary veins creates physically isolated compartments in the lamina (Figure S1). We therefore follow the established nomenclature of heterobaric for MT and homobaric for obv.

\subsection{Irradiance level alters leaf shape and structural parameters differentially in heterobaric and homobaric leaves}

We began by conducting an analysis of leaflet shape between the treatments. A principal component analysis on harmonic coefficients contributing to symmetric shape variation separates MT and obv genotypes but failed to show large differences in shape attributable to light treatment (Figure 2a). To visualize the effects of genotype and light, we superimposed mean leaflet shapes from each genotype-light combination (Figure 2b). obv imparts a wider leaflet shape relative to MT, regardless of light treatment. Light treatment did not discernibly affect leaflet shape.

Sun leaves had reduced total SLA compared with shade leaves in both MT and the obv mutant (Figure 2c). Shading increased SLA values by $101 \%$ and $62 \%$ for MT and obv plants, respectively, when compared with plants in the sun treatment. Terminal leaflets of fully expanded MT sun leaves had 62\% higher perimeter/area than MT shade leaves, unlike obv where we found no difference between 


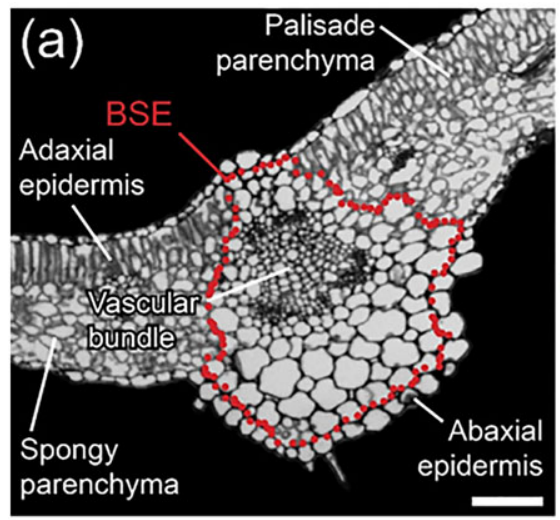

(b)

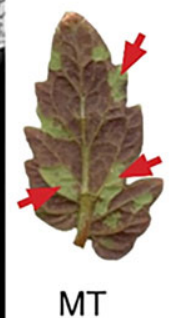

MT

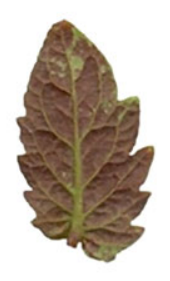

obv

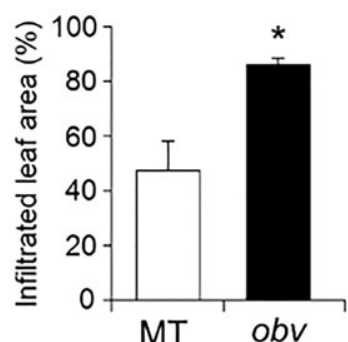

MT obv
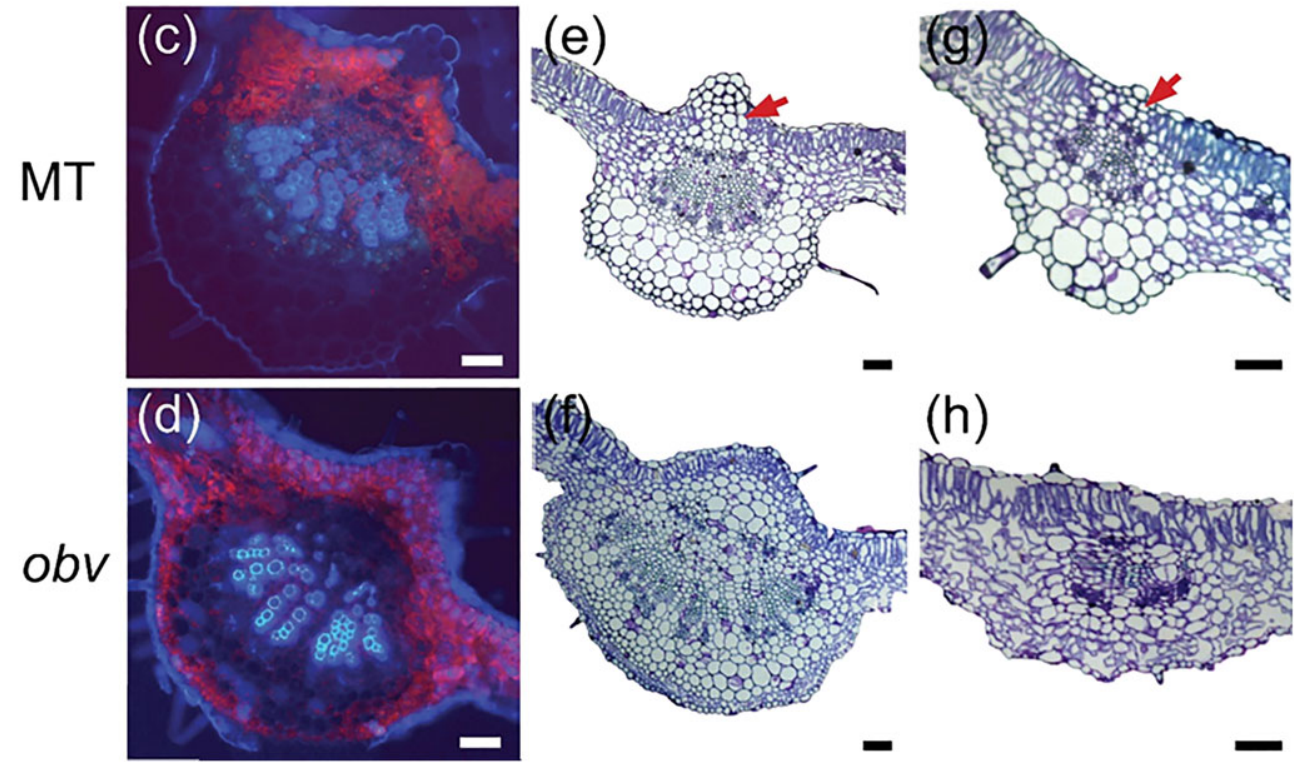

(h)

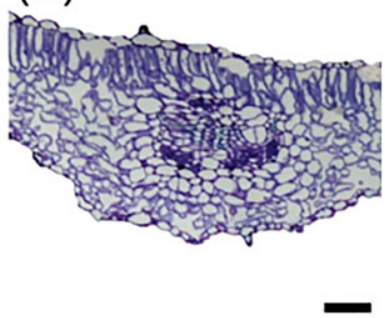

FIGURE 1 Leaf anatomical differences between Micro-Tom (MT) and the obscuravenosa (obv) mutant. (a) Semischematic representation of crosssectional anatomy of a wild-type (MT) secondary vein. BSE: bundle sheath extension. (b) Representative images of terminal leaflets from fully expanded leaves infiltrated with 1\% fuchsin acid solution applying $0.027 \mathrm{MPa}$ of pressure during 2 min showing dry patches (arrowheads) in MT, as opposed to uniform infiltration in obv. Scale bar $=1 \mathrm{~cm}$. Bars are mean values $\pm S E M(n=4)$. Asterisk indicates significant difference by Student's $t$ test $(P<0.05)$. (c) Chlorophyll fluorescence showing interruption of the palisade mesophyll on the adaxial side and of the spongy mesophyll on the abaxial side by BSE cells in MT, which are absent in obv (d). (e-h) Cross sections of the leaf lamina at the midrib (e and f) and a secondary vein ( $\mathrm{g}$ and $\mathrm{h}$ ) show the presence (MT) and absence (obv) of BSEs. The BSEs have a columnar nature protruding toward the adaxial epidermis (arrowheads), with thickened cells walls, whereas they thicken downward and are broadly based upon the lower epidermis. Scale bars $=1 \mathrm{~cm}$ (leaflets) and $100 \mu \mathrm{m}$ (midrib and secondary vein) [Colour figure can be viewed at wileyonlinelibrary.com]

irradiance levels (Figure 2d). Perimeter ${ }^{2} /$ area, which, unlike perimeter/area, is a dimensionless measure of leaf shape (and, therefore, does not inherently scale with size), was strongly dependent on genotype and not influenced by irradiance (Figure 2e).

\section{2 | Growth irradiance alters leaf hydraulic} conductance in heterobaric but not in homobaric leaves in different tomato genetic backgrounds

Leaf hydraulic conductance $\left(K_{\text {leaf }}\right)$ is a key parameter determining plant water relations, as it usually scales up to the whole-plant level (Sack \& Holbrook, 2006). Shading decreased $K_{\text {leaf }}$ in the heterobaric genotype: MT shade leaves had $41 \%$ lower $K_{\text {leaf }}$ than sun leaves $(14.95 \pm 1.91$ vs. $25.36 \pm 1.32 \mathrm{mmol} \mathrm{H}_{2} \mathrm{O} \mathrm{m}^{-2} \mathrm{~s}^{-1} \mathrm{MPa}^{-1}$; Figure 3a,b). Homobaric and heterobaric leaves in the M82 tomato background (Figure 3c) showed a similar leaf vein phenotype as in MT (Figure 3d) and showed consistently similar results, where shade leaves had $36 \%$ lower $K_{\text {leaf }}$ than sun leaves (18.72 \pm 0.59 vs. $29.6 \pm 2.1 \mathrm{mmol} \mathrm{H}_{2} \mathrm{O} \mathrm{m}^{-2} \mathrm{~s}^{-1} \mathrm{MPa}^{-1}$; Figure $3 d$ ). The obv mutant, on the other hand, showed similarly low $K_{\text {leaf }}$ values in either condition and in both genetic backgrounds (MT sun: $17.86 \pm 1.26$ vs. shade: $17.87 \pm 2.14 \mathrm{mmol} \mathrm{H}_{2} \mathrm{O} \mathrm{m}^{-2} \mathrm{~s}^{-1} \mathrm{MPa}^{-1}$; M82: sun: $19.19 \pm 2.24$ vs. shade: $19.17 \pm 2.67 \mathrm{mmol} \mathrm{H}_{2} \mathrm{O} \mathrm{m}^{-2} \mathrm{~s}^{-1} \mathrm{MPa}^{-1}$; Figure $3 \mathrm{~b}, \mathrm{e})$. The results were consistent between tomato backgrounds, even though both cultivars differ markedly in leaf lamina size and other leaf structural parameters.

\subsection{Shading reduces stomatal conductance in heterobaric leaves, whereas homobaric leaves maintain similarly low values under both conditions}

Previous work has suggested that BSEs could influence photosynthetic assimilation rate $(A)$ by increasing light transmission within the 


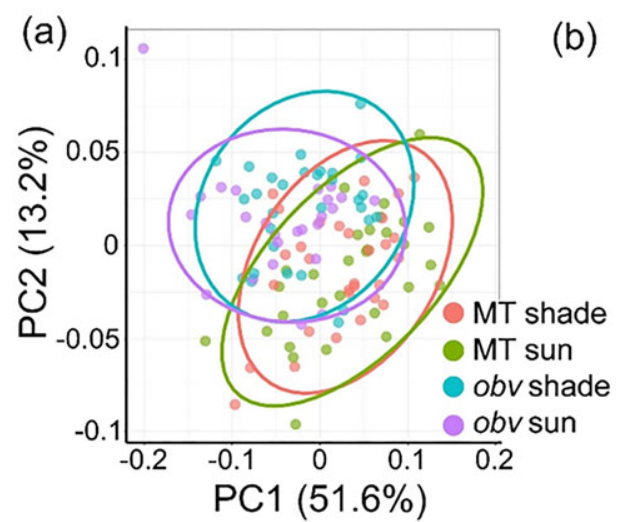

(c)

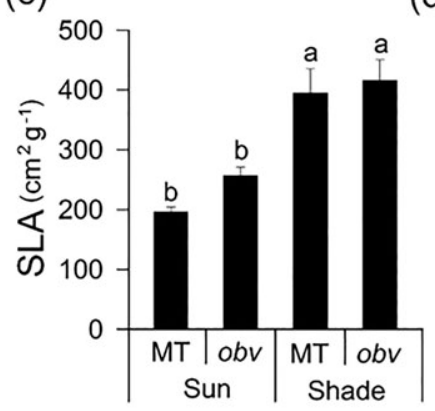

(d)

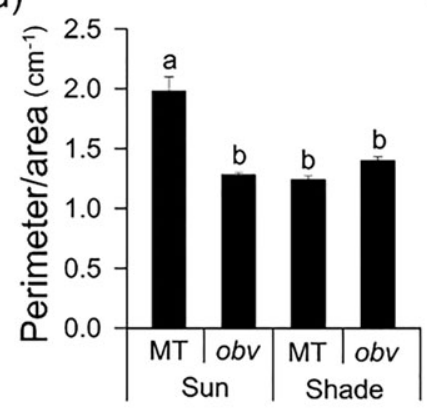

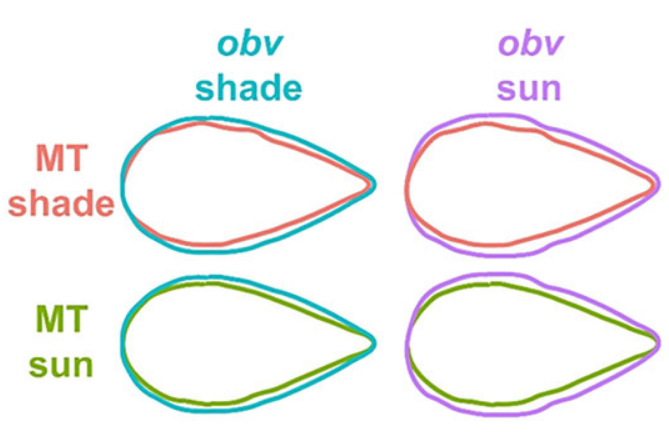

(e)

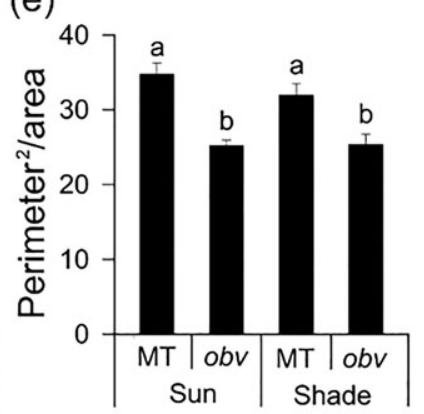

FIGURE 2 Irradiance level differentially alters morphology in heterobaric and homobaric leaves. (a) Principal component analysis (PCA) on A and D harmonic coefficients from an elliptical Fourier descriptor analysis shows distinct symmetric shape differences between Micro-Tom (MT) and obscuravenosa (obv) leaflets but small differences due to light treatment. Ninety-five per cent confidence ellipses are provided for each genotype and light treatment combination, indicated by colour. (b) Mean leaflet shapes for MT and obv in each light treatment. Mean leaflet shapes are superimposed for comparison. Note the wider obv leaflet compared with MT. MT shade, red; MT sun, green; obv shade, blue; obv sun, purple. (c) Specific leaf area (SLA); ( $d$ and e) relationship between perimeter/area and perimeter ${ }^{2} /$ area. Bars are mean values $\pm S E M(n=5)$. Different letters indicate significant differences by Tukey's test at $5 \%$ probability [Colour figure can be viewed at wileyonlinelibrary.com]
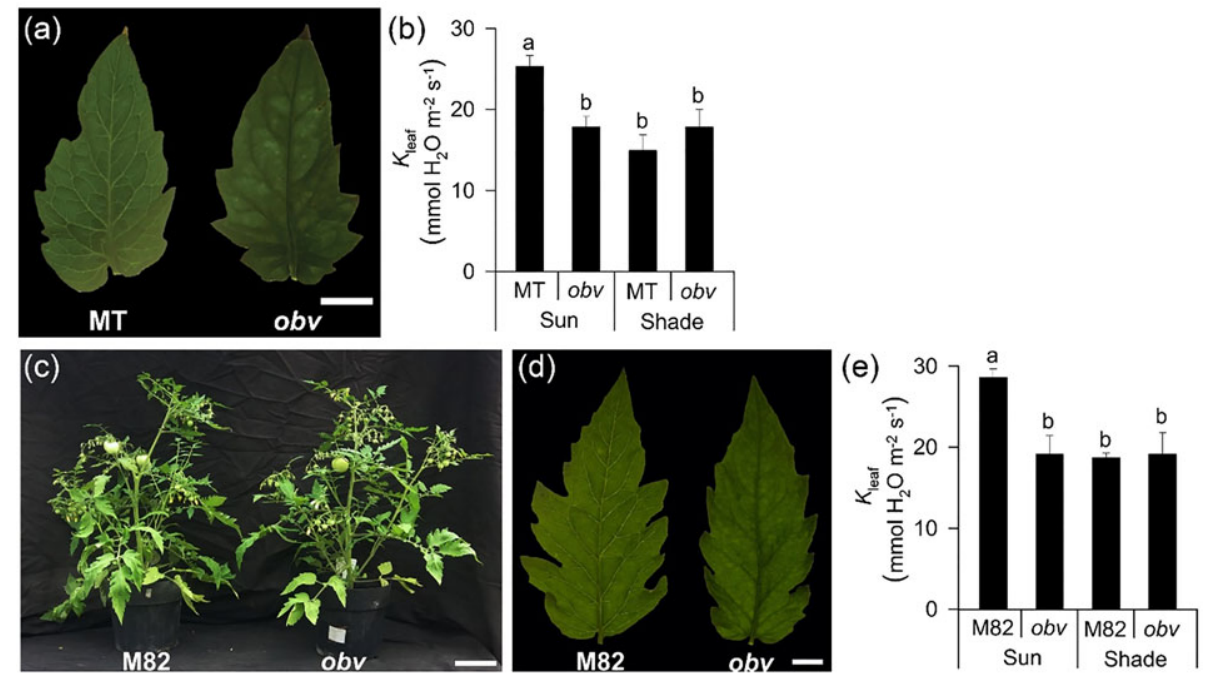

FIGURE 3 (a) Representative terminal leaflets of tomato cultivar Micro-Tom (MT, heterobaric) and the obscuravenosa (obv, homobaric) mutant leaves, showing translucent and dark veins, respectively. Bar $=1 \mathrm{~cm}$. (b) Leaf hydraulic conductance $\left(K_{\text {leaf }}\right)$ in homobaric and heterobaric leaves grown in either sun or shade conditions. Bars are mean values \pm SEM $(n=3)$. Different letters indicate significant differences by Tukey's test at $5 \%$ probability. (c) Representative F1 plants and (b) terminal leaflets of Micro-Tom $\times$ M82 (M82, heterobaric) and Micro-Tom obv $\times$ M82 (obv, homobaric). Scale bars $=10 \mathrm{~cm}$ (c) and $1 \mathrm{~cm}$ (d). (e) $K_{\text {leaf }}$ in $F_{1}$ plants of M82 $\times$ MT (M82, heterobaric) and $F_{1}$ plants of M82 $\times$ MT-obv (obv, homobaric) leaves from plants grown in either sun or shade conditions. Bars are mean values $\pm \operatorname{SEM}(n=5)$. Different letters indicate significant differences by Tukey's $(P<0.05)$ [Colour figure can be viewed at wileyonlinelibrary.com] 
mesophyll (Karabourniotis et al., 2000). To ascertain whether this was the case in our genotypes, we determined photosynthetic light response curves on fully expanded terminal leaflets attached to plants growing in the greenhouse under sun or shade treatments (Figure S1). Although no statistical differences were found in the light response of A between heterobaric MT and homobaric obv plants within the same irradiance treatment (Figure S1), the light saturation point $\left(I_{\mathrm{S}}\right)$ was lower in shade obv than in the other treatments (Table S1).

Because the presence of BSEs can affect lateral flow of $\mathrm{CO}_{2}$ within the leaf blade (Morison et al., 2007; Pieruschka et al., 2006), we next analysed the response of $A$ to varying internal partial pressure of $\mathrm{CO}_{2}$ in the substomatal cavity $\left(C_{\mathrm{i}}\right.$; Table 2$)$. The apparent maximum carboxylation rate of Rubisco $\left(V_{c m a x}\right)$, the maximum potential rate of electron transport in the regeneration of $\operatorname{RuBP}\left(J_{\max }\right)$, and the rate of use of triose-phosphates utilization were reduced by $20.0 \%, 20.2 \%$, and $21.1 \%$, respectively, for shade compared with sun MT plants. In obv, the respective drop between sun and shade plants the same parameters was $10.0 \%, 7.0 \%$, and $6.0 \%$, respectively (Table 2 ).

The hyperbolic relationship between $A$ and $g_{s}$ measured at ambient $\mathrm{CO}_{2}$ was not altered by irradiance level (Figure 4a,b). The lower limit for $g_{\mathrm{s}}$ values was remarkably similar between genotypes in both light conditions $\left(\sim 0.2 \mathrm{~mol} \mathrm{~m}^{-2} \mathrm{~s}^{-1}\right)$. A $30 \%$ decrease in $g_{\mathrm{s}}$ with a concomitant limitation to $A$ was observed in shade MT (Table 2). In the obv mutant, $g_{s}$ was lower in the sun (similar value to shade MT) and remained essentially unchanged by shading, as $\operatorname{did} A$. The $A / g_{s}$ ratio, or intrinsic water-use efficiency $\left(\mathrm{WUE}_{\mathrm{i}}\right)$, was therefore higher in homobaric obv plants than in heterobaric MT under both irradiance levels (Table 2). A similar although not statistically significant difference (possibly owing to the lower number

TABLE 2 Gas exchange parameters determined in fully expanded leaves of heterobaric (Micro-Tom [MT]) and homobaric (obscuravenosa [obv]) in two irradiance levels (sun/shade, $900 / 300 \mu \mathrm{mol}$ photons $\mathrm{m}^{-2} \mathrm{~s}^{-1}$ )

\begin{tabular}{|c|c|c|c|c|}
\hline & \multicolumn{2}{|l|}{ Sun } & \multicolumn{2}{|l|}{ Shade } \\
\hline & MT & $o b v$ & MT & $o b v$ \\
\hline$A\left(\mu \mathrm{mol} \mathrm{CO}{ }_{2} \mathrm{~m}^{-2} \mathrm{~s}^{-1}\right)$ & $21.29 \pm 1.34 a$ & $20.74 \pm 1.44 a$ & $17.07 \pm 0.83 b$ & $20.26 \pm 0.48 a$ \\
\hline $\mathrm{TE}_{\mathrm{i}}\left(\mathrm{A} / \mathrm{g}_{\mathrm{s}}\right)$ & $59.16 \pm 3.25 b$ & $76.26 \pm 2.16 a$ & $65.51 \pm 2.08 b$ & $74.11 \pm 3.55 a$ \\
\hline$V_{c \max }\left(\mu \mathrm{mol} \mathrm{m} \mathrm{m}^{-2} \mathrm{~s}^{-1}\right)$ & $82.7 \pm 6.04 a$ & $80.5 \pm 6.26 a$ & $66.8 \pm 4.38 a$ & $72.7 \pm 7.72 \mathrm{a}$ \\
\hline$J_{\max }\left(\mu \mathrm{mol} \mathrm{m} \mathrm{m}^{-2} \mathrm{~s}^{-1}\right)$ & $167.5 \pm 5.74 a$ & $155.5 \pm 8.48 a$ & $133.5 \pm 4.54 b$ & $130.2 \pm 3.31 b$ \\
\hline$R_{\mathrm{d}}\left(\mu \mathrm{mol} \mathrm{CO} \mathrm{CO}_{2} \mathrm{~m}^{-2} \mathrm{~s}^{-1}\right)$ & $1.49 \pm 0.43 a$ & $1.80 \pm 0.45 a$ & $1.42 \pm 0.38 a$ & $1.45 \pm 0.39 a$ \\
\hline
\end{tabular}

Note. Values are means $\pm \operatorname{SEM}\left(n=8\right.$ for $A, g_{s}$, and TE $;$; $=6$ for other parameters). Values followed by the same letter in each row were not significantly different by Tukey's test at $5 \%$ probability. TPU: triose-phosphate utilization.
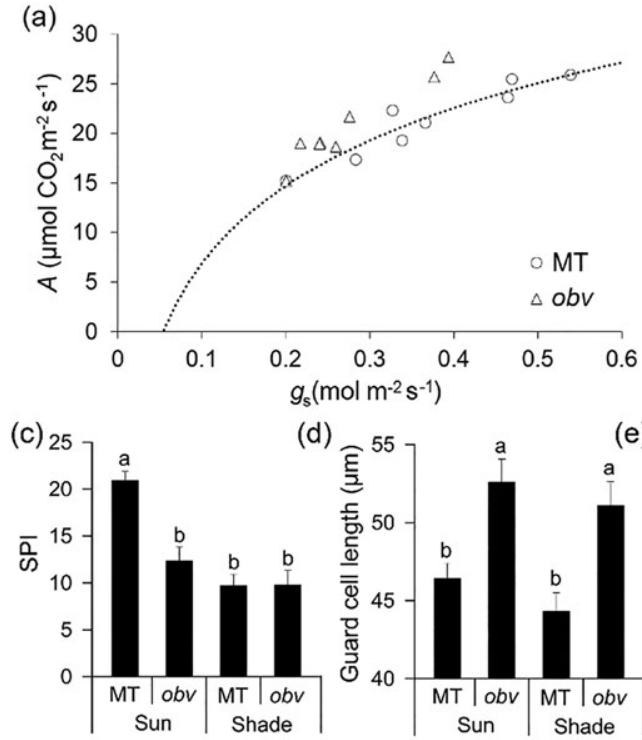

(d)

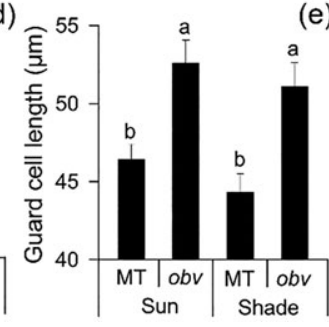

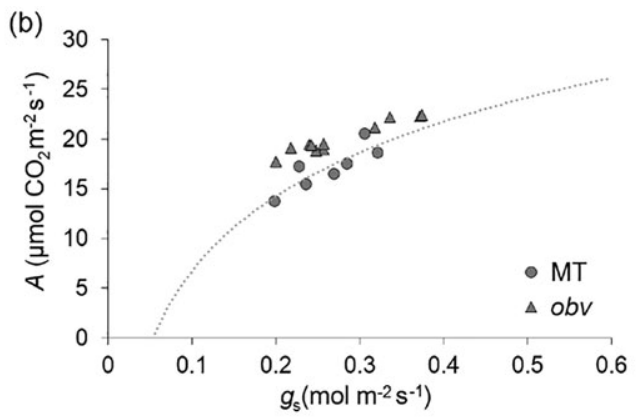

(e)

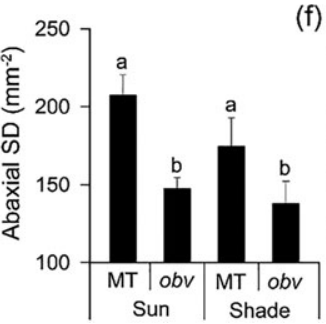

(f)

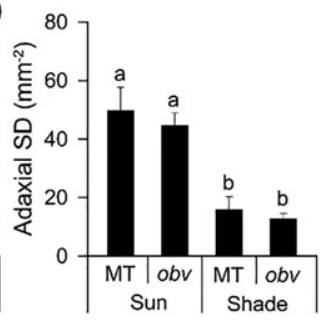

FIGURE 4 Homobaric leaves maintain lower stomatal conductance in both sun and shade conditions. Relationship between photosynthetic $\mathrm{CO}_{2}$ assimilation rate $(A)$ and stomatal conductance $\left(g_{s}\right)$ for Micro-Tom (MT) and the obscuravenosa (obv) mutant plants grown in the sun (a) or shade (b). A rectangular hyperbolic function was fitted in each panel. Each point corresponds to an individual measurement carried out at common conditions in the leaf chamber: photon flux density $\left(1,000 \mu \mathrm{mol} \mathrm{m} \mathrm{m}^{-2} \mathrm{~s}^{-1}\right.$, from a light-emitting diode source), leaf temperature $\left(25 \pm 0.5^{\circ} \mathrm{C}\right)$, leaf-to-

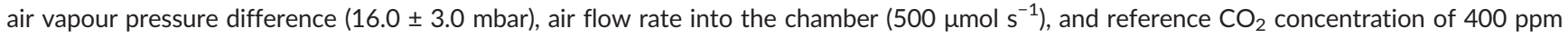
(injected from a cartridge). (c-f) Stomatal traits are differentially affected by irradiance in heterobaric and homobaric tomato leaves. (a) SPI: stomatal pore area index, calculated as (guard cell length) ${ }^{2} \times$ stomatal density for the adaxial and abaxial epidermes and then added up; (b) Guard cell length; (c and d) Stomatal density (number of stomata per unit leaf area); data shown as means \pm SEM $(n=6)$. Different letters indicate significant differences by Tukey's test at $5 \%$ probability 
or replicates, $n=5$ ) was found in M82 (Figure S2). Dark respiration was not affected by genotype or irradiance level (Table 2). The chlorophyll fluorescence analyses revealed a higher quantum yield of photosystem II photochemistry (DPSII) and electron transport rate in homobaric obv plants grown in the sun than in all other treatments. No differences between treatments were found in the photochemical and nonphotochemical quenching (Table S4).

\subsection{SPI is altered by irradiance in heterobaric but not homobaric leaves}

Stomatal conductance $\left(g_{s}\right)$ is influenced by the maximum stomatal conductance $\left(g_{\max }\right)$, which is in turn determined by stomatal size and number (Franks \& Beerling, 2009; Parlange \& Waggoner, 1970). To further explore the basis for the differential $g_{\mathrm{s}}$ response to irradiance between genotypes, we analysed stomatal traits in terminal leaflets of fully expanded leaves (Figure S3). SPI (a combined dimensionless measure of the stomatal density and size) was increased only in MT sun leaves (Figure 4c), compared with all the other treatments. Guard cell length, which is linearly related to the assumed maximum stomatal pore radius, was greater in obv than in MT and was not affected by the irradiance levels (Figure 4d). Thus, the main driver of the difference in SPI was stomatal density, particularly on the abaxial side, which represents a quantitatively large contribution (Figure 4e). Adaxial stomatal density was reduced in the shade in both genotypes, with no differences between them within irradiance levels (Figure 4f).

\section{5 | Minor vein density, modelled mesophyll conductance to $\mathrm{CO}_{2}$, and carbon isotope discrimination are differentially altered by irradiance levels in heterobaric and homobaric leaves}

Leaf lamina thickness was reduced by shading in both genotypes, with no difference between them (Figure 5). These results are in good agreement with the reduced SLA in shade-grown plants (Figure 1c). The palisade-to-spongy mesophyll thickness ratio was increased by shading, independently of genotype (Figure $5 c$ ). Thickness of the abaxial epidermis, a proxy for stomatal depth, did not vary in MT between irradiance levels but was reduced in shaded obv plants (Figure $5 \mathrm{~d}$ ). Intercellular air spaces in the lamina comprised close to $10 \%$ of the cross-sectional area in MT and obv plants grown in the sun, but when plants were grown in the shade, it was increased to $12 \%$ in MT and $17 \%$ in obv (Figure 5e). As venation is a key trait that influences water distribution in the lamina, we assessed minor vein density (tertiary and higher orders) and observed a genotype $x$ irradiance interaction (Figure $5 b$ ). Vein density was reduced in both genotypes by shading but more strongly in MT than in obv (Figure 5f).

We next used anatomical data (Figure S4) to estimate mesophyll conductance to $\mathrm{CO}_{2}\left(g_{\mathrm{m}}\right)$, a key parameter linking leaf hydraulics, photosynthetic function, and leaf anatomy (Flexas, Scoffoni, Gago, \& Sack, 2013; Tomás et al., 2013). Our estimates suggest that the lack of BSEs significantly altered the value of $g_{m}$ in response to shading, whereas the genotypes did not vary significantly for this parameter when grown in the sun (Table 3). As a way to validate our results, and also due to its intrinsic interest as a proxy for $\mathrm{C}_{\mathrm{i}} / \mathrm{C}_{\mathrm{a}}$ (the ratio of $\mathrm{CO}_{2}$ (a)
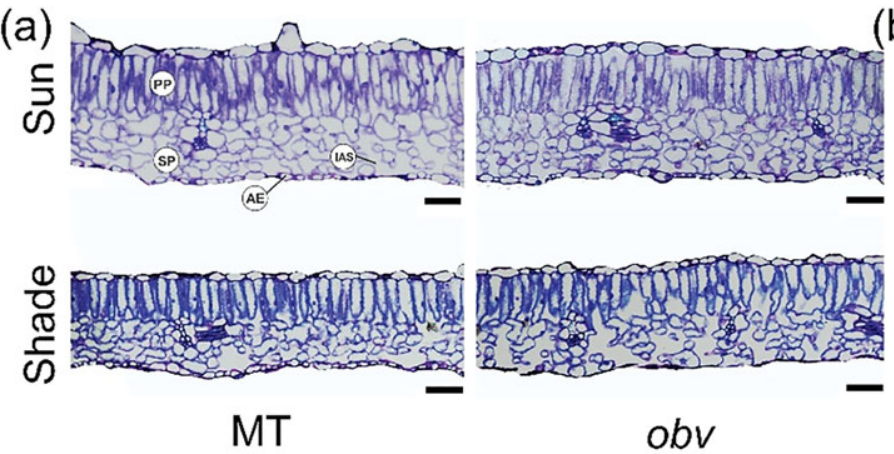

(c)

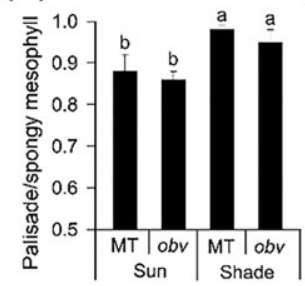

(d)

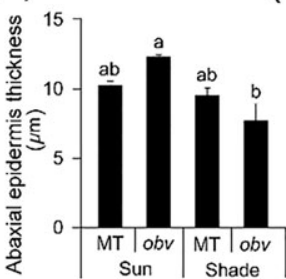

(e)

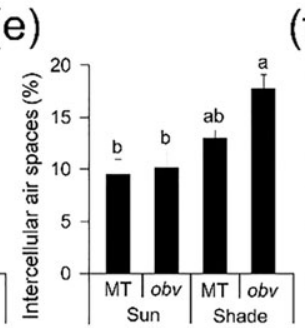

(b)
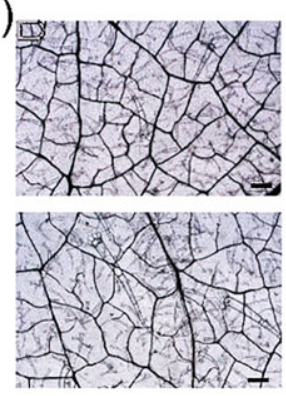

MT
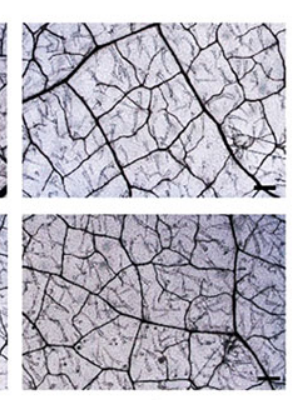

obv (f)

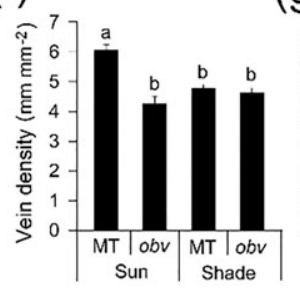

(g)

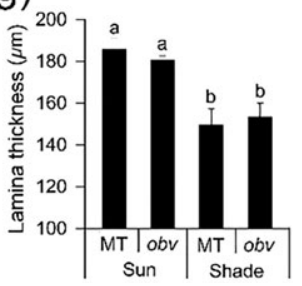

FIGURE 5 Irradiance level differentially alters leaf anatomical parameters in heterobaric and homobaric leaves. (a) Representative cross sections of tomato cultivar Micro-Tom (MT, heterobaric) and the obscuravenosa (obv, homobaric) mutant leaves from plants grown in either sun or shade. The background was removed for clarity. PP: palisade parenchyma; SP: spongy parenchyma; IAS: intercellular air spaces; AE: abaxial epidermis. (b) Representative plates showing the pattern and density of minor veins in 7.8- $\mathrm{mm}^{2}$ sections in mature, cleared leaves. Scale bar $=200 \mu \mathrm{m}$. (c-g) Histograms with mean values \pm SEM $(n=6)$ for the ratio between palisade and spongy parenchyma thickness, thickness of the abaxial epidermis, the proportion of intercellular air spaces, and the density of minor (quaternary and higher order) veins measured in cleared sections of the leaves and lamina thickness. Different letters indicate significant differences by Tukey's test at $5 \%$ probability [Colour figure can be viewed at

wileyonlinelibrary.com] 
TABLE 3 Mesophyll conductance modelled from anatomical characteristics ( $g_{\mathrm{m} \_ \text {anatomical }}$ ), gas phase conductance inside the leaf from substomatal cavities to outer surface of cell walls ( $\left.g_{\text {ias }}\right)$, conductance in liquid and lipid phases from outer surface of cell walls to chloroplasts ( $\left.g_{\text {ias }}\right)$, and mesophyll surface area exposed to intercellular airspace $\left(\mathrm{S}_{\mathrm{m}} / \mathrm{S}\right)$ determined in fully expanded leaves of heterobaric (Micro-Tom [MT]) and homobaric (obscuravenosa [obv]) in two irradiance levels (sun/shade, 900/300 $\mu \mathrm{mol}$ photons $\mathrm{m}^{-2} \mathrm{~s}^{-1}$ )

\begin{tabular}{|c|c|c|c|c|}
\hline & \multicolumn{2}{|l|}{ Sun } & \multicolumn{2}{|l|}{ Shade } \\
\hline & MT & $o b v$ & MT & $o b v$ \\
\hline$g_{\mathrm{m} \_ \text {anatomical }}\left(\mathrm{mol} \mathrm{m}^{-2} \mathrm{~s}^{-1}\right)$ & $0.107 \pm 0.005 c$ & $0.132 \pm 0.005 b$ & $0.124 \pm 0.006 \mathrm{bc}$ & $0.162 \pm 0.004 a$ \\
\hline$g_{\text {liq }}\left(\mathrm{mol} \mathrm{m}^{-2} \mathrm{~s}^{-1}\right)$ & $0.117 \pm 0.006 b$ & $0.170 \pm 0.013 a$ & $0.125 \pm 0.005 b$ & $0.163 \pm 0.007 a$ \\
\hline$S_{\text {mes }} / S\left(m^{2} m^{-2}\right)$ & $6.3 \pm 0.30 b$ & $9.2 \pm 0.72 a$ & $6.8 \pm 0.29 b$ & $8.8 \pm 0.36 a$ \\
\hline
\end{tabular}

Note. Values are means $\pm \operatorname{SEM}(n=4)$. Values followed by the same letter in each row were not significantly different by Tukey's test at $5 \%$ probability.

concentration inside and outside the leaf; Condon, Richards, Rebetzke, \& Farquhar, 2004), we next determined carbon isotope composition $\left(\delta^{13} \mathrm{C}\right)$ in leaves from the same plants used for the anatomy and gas exchange measurements (Table S2). The obv mutation had a differential effect on carbon isotope discrimination $\left(\Delta^{13} \mathrm{C}\right)$, a parameter that is linearly and negatively correlated to long-term WUE of plants. Whereas the presence of the obv mutation increased $\Delta^{13} \mathrm{C}$ in the sun (thus, decreased WUE), it had the opposite effect in the shade (lower $\Delta^{13} \mathrm{C}$ and higher WUE [Figure S5]).

\subsection{Carbohydrate and pigment contents in heterobaric and homobaric leaves under different irradiance}

We assessed a basic set of compounds related to primary cell metabolism in MT and obv under both sun and shade conditions, along with photosynthetic pigments (Table S3). As expected, carbohydrate concentrations were strongly influenced by irradiance level (Table S3). Shading promoted a decrease in starch content in both genotypes but of a considerable greater magnitude in MT $(-45.0 \%)$ than in obv (-28.5\%) compared with sun plants (Table S3). Glucose and fructose were increased in the shade, with no difference between genotypes. The chlorophyll a/b ratio was similar for all plants. A slight increase in carotenoid levels was found in obv shade plants (Table S4).

\section{7 | Morphological and physiological differences between heterobaric and homobaric plant grown under different irradiances do not affect dry mass accumulation or fruit yield}

To determine whether the anatomical and physiological differences described above scale up to the whole-plant level and affect carbon economy and agronomic parameters of tomato, we determined dry mass and fruit yield in sun- and shade-grown plants of MT and obv. There was no difference in plant height or in the number of leaves before the first inflorescence, for plants of either genotype in both light intensities (Table 4). There was a decrease in stem diameter in shade MT and obv plants, compared with sun plants. Leaf insertion angle relative to the stem, however, was steeper in the obv mutant under both irradiance conditions. Different light intensities did not change leaf dry weight; obv plants showed a $24.3 \%$ reduction in stem dry weight, $46.4 \%$ in root dry weight, and $31 \%$ in total dry weight when compared with the sun treatment. The results were similar for $\mathrm{MT}$, so no changes in dry mass allocation pattern were discernible between genotypes. Side branching is one of the most common morphological parameters affected by shading (Casal, 2013). A decrease in side branching was found in both genotypes upon shade treatment, with no differences between them (Figure S6).

Vegetative dry mass accumulation was affected solely by irradiance level with no influence of the genotype and therefore, independent of the presence or absence of BSEs. To ensure that potential

TABLE 4 Plant morphological parameters evaluated 40 days after germination (dag) in heterobaric (Micro-Tom [MT]) and homobaric (obscuravenosa [obv]) tomatoes grown in two irradiance levels (sun/shade, 900/300 $\mu \mathrm{mol}$ photons $\mathrm{m}^{-2} \mathrm{~s}^{-1}$ )

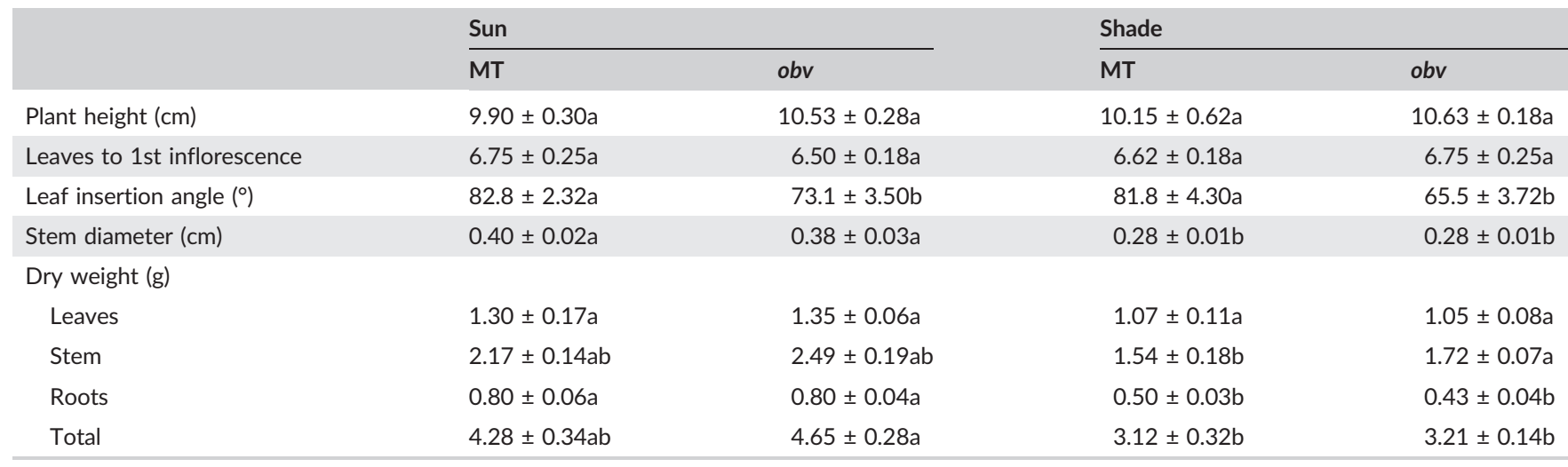

Note. Dry weight was determined through destructive analysis in plants 65 dag $(n=5)$. Values are means \pm SEM $(n=6)$. Values followed by the same letter were not significantly different by Tukey's test at $5 \%$ probability. 
differences arising from altered partitioning or allocation of carbon were not overlooked, we also assessed reproductive traits, that is, parameters related to tomato fruit yield. Average fruit yield per plant was reduced by shading but did not differ between genotypes within each irradiance condition, in two different tomato genetic backgrounds (MT and M82; Table S5). The content of soluble solids in the fruit ( ${ }^{\circ}$ Brix), a parameter of agronomic interest, was also consistently stable across genotypes and treatments.

\section{4 | DISCUSSION}

Heterobaric or homobaric plants are defined based on the presence or absence of BSEs, a structural characteristic associated with certain life forms and ecological distribution. Most of the studies addressing the function of BSEs have been based on large-scale multispecies comparisons, which restricts the conclusions to a statistical effect. Many structural, photosynthetic, and hydraulic leaf traits are strongly coordinated and coselected, therefore reducing the discriminating power of analyses involving species of different life forms and ecological background (Lloyd, Bloomfield, Domingues, \& Farquhar, 2013). Here, we compared different genotypes of a single herbaceous species (tomato) varying for a defined and ecologically relevant leaf structural feature: the presence of BSEs. The obv mutant lacks BSEs and thus produces homobaric leaves, compared with tomato cultivar MT that has heterobaric leaves (Zsögön et al., 2015). We cultivated the plants under contrasting levels of irradiance (sun vs. shade) and investigated leaf structure, hydraulics, and photosynthetic function. We hypothesized that homobaric leaves, lacking a key physical feature that increases carbon assimilation and leaf hydraulic integration, would exhibit less plasticity than heterobaric leaves in their response to environmental conditions.

The presence or absence of BSEs did not affect general leaf morphology in either sun or shade conditions. SLA and leaf shape were altered by irradiance level but without differences between genotypes. A generally higher photosynthetic capacity has been described for heterobaric species (Inoue, Kenzo, Tanaka-Oda, Yoneyama, \& Ichie, 2015), partially attributed to the optical properties of BSEs that enhance light transmission within the leaf mesophyll (Karabourniotis et al., 2000; Nikolopoulos et al., 2002). We did not observe such a photosynthetic advantage for heterobaric plants grown in high irradiance but rather similar $A$ values for both genotypes; indeed, the only difference we found for this genotype was a higher $g_{s}$, which, despite not conferring higher $A$, might be beneficial in terms of latent heat loss, resulting in an improved thermal balance. Shading, on the other hand, reduced $A$ in heterobaric MT plants but not in obv. Because $g_{s}$ and $V_{c \max }$ were identical for both treatments, a higher $A$ could be explained by a higher $g_{\mathrm{m}}$ and, consequently, higher chloroplast $\mathrm{CO}_{2}$ concentration.

We found that obv plants in the shade presented a high amount of intercellular air spaces and a high mesophyll surface area exposed to the intercellular air spaces $\left(S_{\text {mes }} / S\right)$. It seems that the absence of BSEs led to a higher $S_{\text {mes }} / S$ as they allowed more space to become available between palisade cells; on the other hand, presence of BSEs would "push" palisade cells against each other, decreasing their exposure to the intercellular air spaces. An expected outcome of a higher $S_{\text {mes }} / S$ is to increase the anatomical $g_{m}$, as it was the case for the obv plants in the shade (Table S6). However, our alternative $g_{m}$ estimate (using the Ethier method, which takes into account both anatomical and biochemical $g_{m}$ components) did not indicate any difference among plants (Table S6). Such discrepancy between the different estimates might reside in an important contribution from the biochemical components of $g_{m}$, which is believed to be influenced by carbonic anhydrase and aquaporins expression (Flexas, Ribas-Carbó, Diaz-Espejo, Galmés, \& Medrano, 2008; Tomás et al., 2013). In any case, our findings point to the need of further investigation of the role of BSEs on $g_{\mathrm{m}}$ using more refined methodologies (Pons et al., 2009).

In the shade, $g_{s}$ was not changed between genotypes, thus resulting in an enhanced ratio between photosynthetic carbon gain and transpiratory water loss in homobaric obv plants. This observation was borne out by the reduced $\Delta^{13} \mathrm{C}$ in obv compared with the heterobaric MT. Long-term WUE is therefore higher in homobaric plants than in heterobaric plants in the shade, whereas the opposite is true in sun conditions. This provides a reasonable working hypothesis to explain the strongly biased ecological distribution of heterobaric and homobaric species.

The higher incidence of heterobaric species in the canopy of both temperate and tropical forest canopies has been attributed to the effect of BSEs on leaf hydraulic integration (Inoue et al., 2015; Kawai, Miyoshi, \& Okada, 2017; Kenzo et al., 2007). $K_{\text {leaf }}$ was higher in heterobaric than in homobaric sun plants, consistent with the notion that BSEs act as an additional extra-xylematic pathway for the flow of liquid water thus enabling the maintenance of a higher $g_{s}$ (Buckley et al., 2011; Zwieniecki et al., 2007). On the other hand, homobaric and heterobaric leaves showed similar $K_{\text {leaf }}$ values in the shade, indicating that the presence of BSEs differentially affects leaf hydraulic architecture in response to irradiance. $K_{\text {leaf }}$ is dynamically influenced by irradiance over different timescales, in the short term by yet unknown factors (Scoffoni et al., 2008) and in the long term by developmental plasticity altering leaf structural and physiological traits (Scoffoni et al., 2015). Buckley, John, Scoffoni, \& Sack (2015) found that BSEs increased $K_{\text {leaf }}$ by $10 \%$. They found that heterobaric species had $34 \%$ higher $K_{\text {leaf }}$, but this must have been due to traits other than BSEs themselves. Interestingly, under high irradiance (sun), $K_{\text {leaf }}$ was approximately $30 \%$ higher in MT in comparison with obv plants, which is in line with the Buckley et al. (2015) estimates. A possible role for aquaporins present in the BS and/or the mesophyll has been proposed (Cochard et al., 2007), and it is known that aquaporins have their expression reduced under shade (Laur \& Hacke, 2013). Thus, it seems reasonable to assume that other $K_{\text {leaf }}$ components were downregulated under shade, masking the contribution of BSEs to $K_{\text {leaf }}$.

A large set of leaf physiological and structural traits shift in tandem in response to irradiance (Scoffoni et al., 2015). Particularly, plants developing under high light present a higher thermal energy load, which is dissipated mainly through leaf transpiration (Martins et al., 2014). In order to achieve higher transpiration rates, hydraulic supply and demand must be balanced, and vein density and patterning are coordinated with stomatal distribution to optimize resource utilization (Brodribb \& Jordan, 2011). Such coordination occurs across vascular plant species, but exactly how veins and stomata "communicate" with each other remains to be elucidated (Carins 

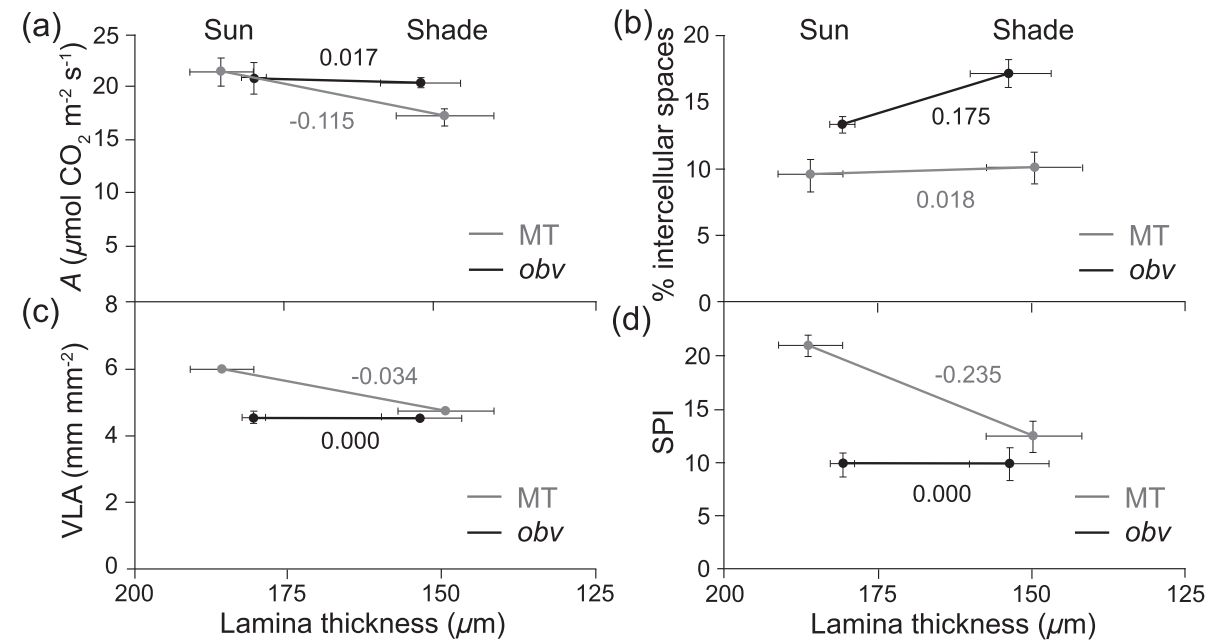

FIGURE 6 Reaction norms of structural and physiological traits in relation to leaf thickness in two irradiance levels in homobaric and heterobaric leaves. (a) Light-saturated photosynthetic assimilation rate (A), (b) proportion of intercellular air spaces in the lamina, (c) minor vein per unit leaf area (VLA), and (d) stomatal pore area index (adimensional). The values of the slopes are shown next to each line. MT: Micro-Tom; obv: obscuravenosa; SPI: stomatal pore area index

Murphy, Dow, Jordan, \& Brodribb, 2017). In this sense, one of the proposed roles of BSEs is to act as a hydraulic linkage route between the vascular bundles and the epidermis, integrating these otherwise separated tissues (Zwieniecki et al., 2007). Here, we found that the presence of BSEs allowed a highly plastic coordination between veins and stomata, up-regulating hydraulic supply and demand under high light (Figure 6). On the other hand, in genotypes lacking BSEs, the abaxial stomata and vein densities remained unchanged (Figure 6). At the moment, there is no evidence to suggest that BSEs are directly responsible for the plasticity in VLA and SPI, nor that if they are responsible, it is because of a hydraulic effect on stomata. That seems unlikely, given that stomatal patterning mostly takes place before leaves begin to expand and transpire substantially. More data are needed to address this point. Another potential structural benefit of BSEs would be the provision of mechanical support, acting analogously to a suspension bridge, partially relieving the vein system from such duty and allowing heterobaric leaves greater flexibility in vein spacing compared with homobaric ones. Thus, the presence of BSEs could represent a hub coordinating trait plasticity in response to irradiance.

An open question is why the structural and physiological effects of the absence of BSEs in a leaf do not scale up to whole-plant carbon economy and growth. In other words, under what set of environmental conditions (if there is one) does the presence or absence of BSEs result in a significant fitness (i.e., survival and reproduction) difference between genotypes? The obv mutation has been incorporated by breeders in many tomato cultivar and hybrids (Jones, Rick, Adams, Jernstedt, \& Chetelat, 2007), suggesting that it can confer some agronomic advantage. The present work was limited to analysing the effect of discrete differences in irradiance and thus represents only a starting point to answering this question. The strong plasticity of plant development in response to irradiance (all other conditions being similar) could be the reason why potential economic differences between genotypes were cancelled out within a given light environment. It is not possible to rule out that stronger quantitative differences in irradiance levels other than the ones tested here could tilt the phenotypic and fitness scales in favour of one of the leaf designs (i.e. heterobaric/homobaric). Alternatively, other variables (e.g., water and nitrogen availability and ambient $\mathrm{CO}_{2}$ concentration) and combinations thereof could result in conditions where the difference in leaf structure scales up to the whole-plant level. Given the presumed hydraulic benefit of BSEs, situations where the hydraulic system is pushed to the limit (e.g., high evaporative demand) might be useful to maximize the benefit of BSEs. We endeavour to address these questions in the near future.

\section{5 | CONCLUSIONS}

The presence of BSEs in heterobaric tomato plants is coordinated with plastic variation in both structural and physiological leaf traits under different growth irradiance levels. Irradiance level altered mainly stomata pore index, minor vein density, and leaf hydraulic conductance in heterobaric plants and leaf intercellular air spaces, modelled mesophyll conductance, and photosynthetic assimilation rate in homobaric plants. This variation, however, allows both genotypes to maintain leaf physiological performance and growth under both irradiance conditions and results in the carbon economy and allocation of either genotype being indistinguishable within each irradiance level. Further insight into this fascinating complexity will come when the genetic basis for BSE development is unveiled.

\section{ACKNOWLEDGEMENTS}

This work was funded by a grant (RED-00053-16) from the Foundation for Research Assistance of the Minas Gerais State (FAPEMIG, Brazil). L. E. P. P. acknowledges a grant (307040/2014-3) from the National Council for Scientific and Technological Development (CNPq, Brazil). 


\section{AUTHOR CONTRIBUTIONS}

M. A. M. B. and D. H. C. conducted experiments and prepared figures and/or tables. A. A. A., W. L. A., D. M. R., S. C. V. M., and L. E. P. P. designed experiments, contributed reagents/materials/analysis tools, and reviewed drafts of the paper. A. Z. conceived and designed the experiments, analysed the data, and wrote the paper with contributions from the other authors.

\section{ORCID}

Wagner L. Araújo (iD https://orcid.org/0000-0002-4796-2616

Dimas M. Ribeiro (ID https://orcid.org/0000-0002-8999-5547

Agustin Zsögön (DD https://orcid.org/0000-0001-7828-7425

\section{REFERENCES}

Abramoff, M. D., Magalhães, P. J., \& Ram, S. J. (2004). Biophotonics international. Biophotonics International, 11, 36-42.

Berghuijs, H. N. C., Yin, X., Tri Ho, Q., van der Putten, P. E. L., Verboven, P., Retta, M. A., ... Struik, P. C. (2015). Modelling the relationship between $\mathrm{CO} 2$ assimilation and leaf anatomical properties in tomato leaves. Plant Science, 238, 297-311.

Bonhomme, V., Picq, S., Gaucherel, C., Claude, J., Bonhomme, V., Picq, S., .. Claude, J. (2014). Momocs: Outline analysis using R. Journal of Statistical Software, 56, 1-24.

Brodribb, T. J., \& Jordan, G. J. (2011). Water supply and demand remain balanced during leaf acclimation of Nothofagus cunninghamii trees. New Phytologist, 192, 437-448.

Buckley, T. N., Sack, L., \& Gilbert, M. E. (2011). The role of bundle sheath extensions and life form in stomatal responses to leaf water status. Plant Physiology, 156, 962-973.

Buckley, T. N., John, G. P., Scoffoni, C., \& Sack, L. (2015). How does leaf anatomy influence water transport outside the xylem? Plant Physiology, $168,1616-1635$

Carins Murphy, M., Dow, G., Jordan, G., \& Brodribb, T. (2017). Vein density is independent of epidermal cell size in Arabidopsis mutants. Functional Plant Biology, 44, 410-418.

Carvalho, R. F., Campos, M. L., Pino, L. E., Crestana, S. L., Zsögön, A., Lima, J. E., ... Peres, L. E. (2011). Convergence of developmental mutants into a single tomato model system: "Micro-Tom" as an effective toolkit for plant development research. Plant Methods, 7, 18.

Casal, J. J. (2013). Photoreceptor signaling networks in plant responses to shade. Annual Review of Plant Biology, 64, 403-427.

Chitwood, D. H., Kumar, R., Ranjan, A., Pelletier, J. M., Townsley, B. T., Ichihashi, Y., ... Sinha, N. R. (2015). Light-induced indeterminacy alters shade-avoiding tomato leaf morphology. Plant Physiology, 169, 2030-2047.

Cochard, H., Venisse, J.-S., Barigah, T. S., Brunel, N., Herbette, S., Guilliot, A., ... Sakr, S. (2007). Putative role of aquaporins in variable hydraulic conductance of leaves in response to light. Plant Physiology, 143 122-133.

Condon, A. G., Richards, R. A., Rebetzke, G. J., \& Farquhar, G. D. (2004). Breeding for high water-use efficiency. Journal of Experimental Botany, $55,2447-2460$

Eid Gamel, R., Elsayed, A., Bashasha, J., \& Haroun, S. (2016). Priming tomato cultivars in $\beta$-sitosterol or gibberellic acid improves tolerance for temperature stress. International Journal of Botany, 13, 1-14.

Esau, K. (1977). Anatomy of seed plants (2nd ed.). New York: John Wiley \& Sons, Inc.

Ethier, G. J., \& Livingston, N. J. (2004). On the need to incorporate sensitivity to $\mathrm{CO} 2$ transfer conductance into the Farquhar-von CaemmererBerry leaf photosynthesis model. Plant, Cell and Environment, 27, 137-153.
Evans, J., Caemmerer, S., Setchell, B., \& Hudson, G. (1994). The relationship between $\mathrm{CO}_{2}$ transfer conductance and leaf anatomy in transgenic tobacco with a reduced content of Rubisco. Australian Journal of Plant Physiology, 21, 475.

Evans, J. R., \& Poorter, H. (2001). Photosynthetic acclimation of plants to growth irradiance: The relative importance of specific leaf area and nitrogen partitioning in maximizing carbon gain. Plant, Cell and Environment, 24, 755-767.

Farquhar, G. D., \& Sharkey, T. D. (1982). Stomatal conductance and photosynthesis. Annual Review of Plant Physiology, 33, 317-345.

Farquhar, G. D., von Caemmerer, S., \& Berry, J. A. (1980). A biochemical model of photosynthetic $\mathrm{CO} 2$ assimilation in leaves of $\mathrm{C} 3$ species. Planta, 149, 78-90.

Fernie, A. R., Roscher, A., Ratcliffe, R. G., \& Kruger, N. J. (2001). Fructose 2,6-bisphosphate activates pyrophosphate: Fructose-6-phosphate 1phosphotransferase and increases triose phosphate to hexose phosphate cycling heterotrophic cells. Planta, 212, 250-263.

Flexas, J., Ribas-Carbó, M., Diaz-Espejo, A., Galmés, J., \& Medrano, H. (2008). Mesophyll conductance to $\mathrm{CO} 2$ : Current knowledge and future prospects. Plant, Cell and Environment, 31, 602-621.

Flexas, J., Scoffoni, C., Gago, J., \& Sack, L. (2013). Leaf mesophyll conductance and leaf hydraulic conductance: An introduction to their measurement and coordination. Journal of Experimental Botany, 64, 3965-3981.

Franks, P. J., \& Beerling, D. J. (2009). Maximum leaf conductance driven by $\mathrm{CO} 2$ effects on stomatal size and density over geologic time. Proceedings of the National Academy of Sciences U.S.A., 106, 10343-10347.

Galmés, J., Ochogavía, J. M., Gago, J., Roldán, E. J., Cifre, J., \& Conesa, M. À. (2013). Leaf responses todrought stress in Mediterranean accessions of Solanum lycopersicum: Anatomical adaptations in relation to gas exchange parameters. Plant, Cell and Environment, 36, 920-935.

Genty, B., Briantais, J.-M., \& Baker, N. R. (1989). The relationship between the quantum yield of photosynthetic electron transport and quenching of chlorophyll fluorescence. Biochimica et Biophysica Acta (BBA) - General Subjects, 990, 87-92.

Guyot, G., Scoffoni, C., \& Sack, L. (2012). Combined impacts of irradiance and dehydration on leaf hydraulic conductance: Insights into vulnerability and stomatal control. Plant, Cell and Environment, 35, 857-871.

Hacker, J., \& Neuner, G. (2007). Ice propagation in plants visualized at the tissue level by infrared differential thermal analysis (IDTA). Tree Physiology, 27, 1661-1670.

Inoue, Y., Kenzo, T., Tanaka-Oda, A., Yoneyama, A., \& Ichie, T. (2015). Leaf water use in heterobaric and homobaric leafed canopy tree species in a Malaysian tropical rain forest. Photosynthetica, 53, 177-186.

Iwata, H., Niikura, S., Matsuura, S., Takano, Y., \& Ukai, Y. (1998). Evaluation of variation of root shape of Japanese radish (Raphanus sativus L.) based on image analysis using elliptic Fourier descriptors. Euphytica, 102, 143-149.

Iwata, H., \& Ukai, Y. (2002). SHAPE: A computer program package for quantitative evaluation of biological shapes based on elliptic fourier descriptors. Journal of Heredity, 93, 384-385.

Jones, C. M., Rick, C. M., Adams, D., Jernstedt, J., \& Chetelat, R. T. (2007). Genealogy and fine mapping of Obscuravenosa, a gene affecting the distribution of chloroplasts in leaf veins and evidence of selection during breeding of tomatoes (Lycopersicon esculentum; Solanaceae). American Journal of Botany, 94, 935-947.

Karabourniotis, G., Bornman, J. F., \& Nikolopoulos, D. (2000). A possible optical role of the bundle sheath extensions of the heterobaric leaves of Vitis vinifera and Quercus coccifera. Plant, Cell and Environment, $23,423-430$

Kawai, K., Miyoshi, R., \& Okada, N. (2017). Bundle sheath extensions are linked to water relations but not to mechanical and structural properties of leaves. Trees, 31, 1-11. 
Kenzo, T., Ichie, T., Watanabe, Y., \& Hiromi, T. (2007). Ecological distribution of homobaric and heterobaric leaves in tree species of Malaysian lowland tropical rainforest. American Journal of Botany, 94, 764-775.

Laur, J., \& Hacke, U. G. (2013). Transpirational demand affects aquaporin expression in poplar roots. Journal of Experimental Botany, 64 2283-2293.

Lawson, T., \& Morison, J. (2006). Visualising patterns of CO2 diffusion in leaves. New Phytologist, 169, 641-643.

Leegood, R. C. (2008). Roles of the bundle sheath cells in leaves of C3 plants. Journal of Experimental Botany, 59, 1663-1673.

Lloyd, J., Bloomfield, K., Domingues, T. F., \& Farquhar, G. D. (2013). Photosynthetically relevant foliar traits correlating better on a mass vs an area basis: Of ecophysiological relevance or just a case of mathematical imperatives and statistical quicksand? New Phytologist, 199, 311-321.

Martins, S. C. V., Galmés, J., Cavatte, P. C., Pereira, L. F., Ventrella, M. C., \& DaMatta, F. M. (2014). Understanding the low photosynthetic rates of sun and shade coffee leaves: Bridging the gap on the relative roles of hydraulic, diffusive and biochemical constraints to photosynthesis. PLoS ONE, 9, e95571.

McAdam, S. A. M., Eléouët, M. P., Best, M., Brodribb, T. J., Murphy, M. C., Cook, S. D., ... Urquhart, S. (2017). Linking auxin with photosynthetic rate via leaf venation. Plant Physiology, 175, 351-360.

Morison, J. I. L., Lawson, T., \& Cornic, G. (2007). Lateral CO2 diffusion inside dicotyledonous leaves can be substantial: Quantification in different light intensities. Plant Physiology, 145, 680-690.

Neger, F. (1918). Wegsamkeit der Laubblätter für Gase. Flora, 111, 152-161.

Nicotra, A. B., Leigh, A., Boyce, C. K., Jones, C. S., Niklas, K. J., Royer, D. L., \& Tsukaya, H. (2011). The evolution and functional significance of leaf shape in the angiosperms. Functional Plant Biology, 38, 535-552.

Nicotra, A. B., Cosgrove, M. J., Cowling, A., Schlichting, C. D., \& Jones, C. S. (2008). Leaf shape linked to photosynthetic rates and temperature optima in South African Pelargonium species. Oecologia, 154, 625.

Niinemets, Ü. (2012). Optimization of foliage photosynthetic capacity in tree canopies: Towards identifying missing constraints. Tree Physiology, 32, 505-509.

Niinemets, Ü., Cescatti, A., Rodeghiero, M., \& Tosens, T. (2006). Complex adjustments of photosynthetic potentials and internal diffusion conductance to current and previous light availabilities and leaf age in Mediterranean evergreen species Quercus ilex. Plant, Cell and Environment, 29, 1159-1178.

Niinemets, Ü., \& Reichstein, M. (2003). Controls on the emission of plant volatiles through stomata: Differential sensitivity of emission rates to stomatal closure explained. Journal of Geophysical Research, 108, 4208.

Niinemets, Ü., \& Sack, L. (2006). Structural determinants of leaf lightharvesting capacity and photosynthetic potentials. In Progress in botany (pp. 385-419). Berlin/Heidelberg: Springer-Verlag.

Nikolopoulos, D., Liakopoulos, G., Drossopoulos, I., \& Karabourniotis, G. (2002). The relationship between anatomy and photosynthetic performance of heterobaric leaves. Plant Physiology, 129, 235-243.

Nunes-Nesi, A., de Laia Nascimento, V., de Oliveira Silva, F. M., Zsögön, A., Araújo, W. L., \& Sulpice, R. (2016). Natural genetic variation for morphological and molecular determinants of plant growth and yield. Journal of Experimental Botany, 67, 2989-3001.

Oguchi, R., Hikosaka, K., \& Hirose, T. (2003). Does the photosynthetic light-acclimation need change in leaf anatomy? Plant, Cell and Environment, 26, 505-512.

Oguchi, R., Hikosaka, K., \& Hirose, T. (2005). Leaf anatomy as a constraint for photosynthetic acclimation: Differential responses in leaf anatomy to increasing growth irradiance among three deciduous trees. Plant, Cell and Environment, 28, 916-927.

Oguchi, R., Hikosaka, K., Hiura, T., \& Hirose, T. (2006). Leaf anatomy and light acclimation in woody seedlings after gap formation in a cooltemperate deciduous forest. Oecologia, 149, 571-582.
Ohtsuka, A., Sack, L., \& Taneda, H. (2018). Bundle sheath lignification mediates the linkage of leaf hydraulics and venation. Plant, Cell and Environment, 41, 342-353.

Parlange, J. Y., \& Waggoner, P. E. (1970). Stomatal dimensions and resistance to diffusion. Plant Physiology, 46, 337-342.

Pieruschka, R., Schurr, U., Jensen, M., Wolff, W. F., \& Jahnke, S. (2006). Lateral diffusion of $\mathrm{CO} 2$ from shaded to illuminated leaf parts affects photosynthesis inside homobaric leaves. New Phytologist, 169, 779-787.

Pons, T. L., Flexas, J., von Caemmerer, S., Evans, J. R., Genty, B., RibasCarbo, M., \& Brugnoli, E. (2009). Estimating mesophyll conductance to $\mathrm{CO}_{2}$ : Methodology, potential errors, and recommendations. Journal of Experimental Botany, 60, 2217-2234.

Porra, R. J., Thompson, W. A., \& Kriedemann, P. E. (1989). Determination of accurate extinctioncoefficients and simultaneous equations for assaying chlorophylls $a$ and $b$ extracted with four different solvents: Verification of the concentration of chlorophyll standards by atomic absorption spectroscopy. Biochimica et Biophysica Acta, 975, 384-394.

Prado, K., \& Maurel, C. (2013). Regulation of leaf hydraulics: From molecular to whole plant levels. Frontiers in Plant Science, 4, 255.

Praxedes, S. C., DaMatta, F. M., Loureiro, M. E., Ferrão, M. A. G., \& Cordeiro, A. T. (2006). Effects of long-term soil drought on photosynthesis and carbohydrate metabolism in mature robusta coffee (Coffea canephora Pierre var. kouillou) leaves. Environmental and Experimental Botany, 56, 263-273.

Quentin, A. G., Pinkard, E. A., Ryan, M. G., Tissue, D. T., Baggett, L. S., Adams, H. D., ... Woodruff, D. R. (2015). Non-structural carbohydrates in woody plants compared among laboratories. Tree Physiology, 35, 1146-1165.

R Core Team (2018). R: A language and environment for statistical computing.

Read, J., \& Stokes, A. (2006). Plant biomechanics in an ecological context. American Journal of Botany, 93, 1546-1565.

Rodeghiero, M., Niinemets, Ü., \& Cescatti, A. (2007). Major diffusion leaks of clamp-on leaf cuvettes still unaccounted: How erroneous are the estimates of Farquhar et al. model parameters? Plant, Cell and Environment, 30, 1006-1022.

Ronchi, C. P., DaMatta, F. M., Batista, K. D., Moraes, G. A. B. K., Loureiro, M. E., \& Ducatti, C. (2006). Growth and photosynthetic downregulation in Coffea arabica in response to restricted root volume. Functional Plant Biology, 33, 1013-1023.

Sack, L., Cowan, P. D., Jaikumar, N., \& Holbrook, N. M. (2003). The "hydrology" of leaves: Co-ordination of structure and function in temperate woody species. Plant, Cell and Environment, 26, 1343-1356.

Sack, L., \& Frole, K. (2006). Leaf structural diversity is related to hydraulic capacity in tropical rain forest trees. Ecology, 87, 483-491.

Sack, L., \& Holbrook, N. M. (2006). Leaf hydraulics. Annual Review of Plant Biology, 57, 361-381.

Sack, L., Scoffoni, C., McKown, A. D., Frole, K., Rawls, M., Havran, J. C., ... Tran, T. (2012). Developmentally based scaling of leaf venation architecture explains global ecological patterns. Nature Communications, 3, 837.

Schlichting, C. D. (1986). The evolution of phenotypic plasticity in plants. Annual Review of Ecology and Systematics, 17, 667-693.

Scoffoni, C., Albuquerque, C., Brodersen, C. R., Townes, S. V., John, G. P., Bartlett, M. K., ... Sack, L. (2017). Outside-xylem vulnerability, not xylem embolism, controls leaf hydraulic decline during dehydration. Plant Physiology, 173, 1197-1210.

Scoffoni, C., Kunkle, J., Pasquet-Kok, J., Vuong, C., Patel, A. J., Montgomery, R. A., ... Sack, L. (2015). Light-induced plasticity in leaf hydraulics, venation, anatomy, and gas exchange in ecologically diverse Hawaiian lobeliads. New Phytologist, 207, 43-58.

Scoffoni, C., Pou, A. L., Cia, A. K. R., \& Sack, L. (2008). The rapid light response of leaf hydraulic conductance: New evidence from two experimental methods. Plant, Cell and Environment, 31, 1803-1812. 
Shipley, B. (2002). Trade-offs between net assimilation rate and specific leaf area in determining relative growth rate: Relationship with daily irradiance. Functional Ecology, 16, 682-689.

Silva, W. B., Vicente, M. H., Robledo, J. M., Reartes, D. S., Ferrari, R. C., Bianchetti, R., ... Zsögön, A. (2018). SELF-PRUNING acts synergistically with DIAGEOTROPICA to guide auxin responses and proper growth form. Plant Physiology, 176, 2904-2916.

Terashima, I. (1992). Anatomy of nonuniform leaf photosynthesis. Photosynthesis Research, 31, 195-212.

Terashima, I., Hanba, Y. T., Tazoe, Y., Vyas, P., \& Yano, S. (2006). Irradiance and phenotype: Comparative eco-development of sun and shade leaves in relation to photosynthetic $\mathrm{CO} 2$ diffusion. Journal of Experimental Botany, 57, 343-354.

Terashima, I., Hanba, Y. T., Tholen, D., \& Niinemets, Ü. (2011). Leaf functional anatomy in relation to photosynthesis. Plant Physiology, 155, 108-116.

Terashima, I., Miyazawa, S.-I., \& Hanba, Y. T. (2001). Why are sun leaves thicker than shade leaves? Consideration based on analyses of $\mathrm{CO}_{2}$ diffusion in the leaf. Journal of Plant Research, 114, 93-105.

Thain, J. F. (1983). Curvature correction factors in the measurement of cell surface areas in plant tissues. Journal of Experimental Botany, 34, 87-94.

Tomás, M., Flexas, J., Copolovici, L., Galmés, J., Hallik, L., Medrano, H., ... Niinemets, Ü. (2013). Importance of leaf anatomy in determining mesophyll diffusion conductance to $\mathrm{CO}_{2}$ across species: Quantitative limitations and scaling up by models. Journal of Experimental Botany, 64, 2269-2281.

Tosens, T., Niinemets, U., Vislap, V., Eichelmann, H., \& Castro, D. P. (2012). Developmental changes in mesophyll diffusion conductance and photosynthetic capacity under different light and water availabilities in Populus tremula: How structure constrains function. Plant, Cell and Environment, 35, 839-856.

Trifiló, P., Raimondo, F., Savi, T., Lo Gullo, M. A., \& Nardini, A. (2016). The contribution of vascular and extra-vascular water pathways to droughtinduced decline of leaf hydraulic conductance. Journal of Experimental Botany, 67, 5029-5039.
Valladares, F., Gianoli, E., \& Gómez, J. M. (2007). Ecological limits to plant phenotypic plasticity. New Phytologist, 176, 749-763.

Vicente, M. H., Zsögön, A., Lopo de Sá, A. F., Ribeiro, R. V., \& Peres, L. E. P. (2015). Semi-determinate growth habit adjusts the vegetative-toreproductive balance and increases productivity and water-use efficiency in tomato (Solanum lycopersicum). Journal of Plant Physiology, 177, 11-19.

Wickham, H. (2016). ggplot2: Elegant graphics for data analysis (2nd ed.). New York, USA: Springer.

Wylie, R. B. (1943). The role of the epidermis in foliar organization and its relations to the minor venation. American Journal of Botany, 30, 273-280.

Wylie, R. B. (1952). The bundle sheath extension in leaves of dicotyledons. American Journal of Botany, 39, 645-651.

Zsögön, A., Alves Negrini, A. C., Peres, L. E. P., Nguyen, H. T., \& Ball, M. C. (2015). A mutation that eliminates bundle sheath extensions reduces leaf hydraulic conductance, stomatal conductance and assimilation rates in tomato (Solanum lycopersicum). New Phytologist, 205, 618-626.

Zwieniecki, M. A., Brodribb, T. J., \& Holbrook, N. M. (2007). Hydraulic design of leaves: Insights from rehydration kinetics. Plant, Cell and Environment, 30, 910-921.

\section{SUPPORTING INFORMATION}

Additional supporting information may be found online in the Supporting Information section at the end of the article.

How to cite this article: Barbosa MAM, Chitwood DH, Azevedo AA, et al. Bundle sheath extensions affect leaf structural and physiological plasticity in response to irradiance. Plant Cell Environ. 2018;1-15. https://doi.org/10.1111/pce.13495 